Treatability Study Work Plan for In Situ Vitrification of Seepage Pit 1 in Waste Area Grouping 7 at Oak Ridge National Laboratory, Oak Ridge, Tennessee

B. P. Spalding

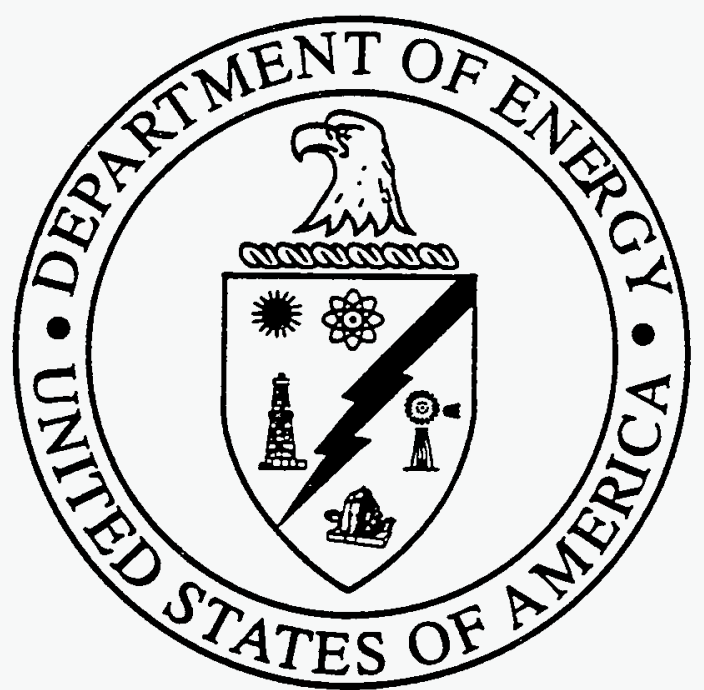


This report has been reproduced directly from the best available copy.

Available to DOE and DOE contractors from the Office of Scientific and Technical Information, P.O. Box 62, Oak Ridge, TN 37831; prices avallable from $615-576-8401$.

Available to the public from the National Technical Information Service, U.S. Department of Commerce, 5285 Port Royal Rd., Springfield, VA 22161. 


\section{DISCLAIMER}

Portions of this document may be illegible in electronic image products. Images are produced from the best available original document. 
Energy Systems Environmental Restoration Program

ORNL Environmental Restoration Program

\title{
Treatability Study Work Plan for In Situ Vitrification of Seepage Pit 1 in Waste Area Grouping 7 at Oak Ridge National Laboratory, Oak Ridge, Tennessee
}

\author{
B. P. Spalding
}

Date Issued-July 1994

\begin{abstract}
Prepared by
Environmental Sciences Division

Oak Ridge National Laboratory

ESD Publication 4157
\end{abstract}

Prepared for

U.S. Department of Energy

Office of Environmental Restoration and Waste Management under budget and reporting code EW 20

Environmental Restoration and Waste Management Programs Oak Ridge National Laboratory

Oak Ridge, Tennessee 37831-6285

managed by

MARTIN MARIETTA ENERGY SYSTEMS, INC.

for the

U.S. DEPARTMENT OF ENERGY

under contract DE-AC05-84OR21400 


\begin{abstract}
Author Affiliation
B. P. Spalding is a member of the Environmental Sciences Division of Oak Ridge National Laboratory, which is managed by Martin Marietta Energy Systems, Inc.
\end{abstract}

DISCLAIMER

This report was prepared as an account of work sponsored by an agency of the United States Government. Neither the United States Government nor any agency thereof, nor any of their employees, makes any warranty, express or implied, or assumes any legal liability or responsibility for the accuracy, completeness, or usefulness of any information, apparatus, product, or process disclosed, or represents that its use would not infringe privately owned rights. Reference herein to any specific commercial product, process, or service by trade name, trademark, manufacturer, or otherwise does not necessarily constitute or imply its endorsement, recommendation, or favoring by the United States Government or any agency thereof. The views and opinions of authors expressed herein do not necessarily state or reflect those of the United States Government or any agency thereof. 


\section{CONTENTS}

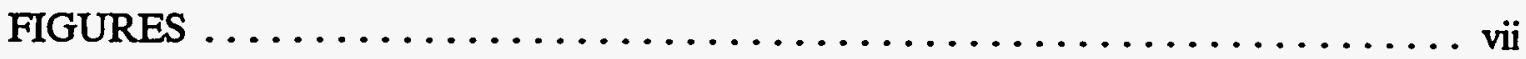

EXECUTIVE SUMMARY $\ldots \ldots \ldots \ldots \ldots \ldots \ldots \ldots \ldots \ldots \ldots \ldots \ldots \ldots \ldots \ldots$

1. PROJECT DESCRIPTION $\ldots \ldots \ldots \ldots \ldots \ldots \ldots \ldots \ldots \ldots \ldots \ldots \ldots$

2. REMEDIAL TECHNOLOGY DESCRIPTION $\ldots \ldots \ldots \ldots \ldots \ldots \ldots$

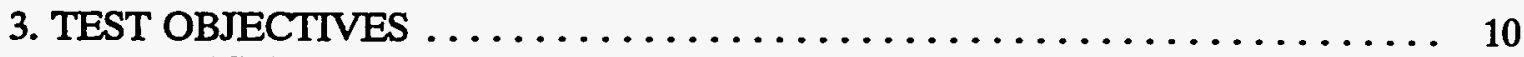

3.1 ISV MELT DEPTH CAPABILITY DEMONSTRATION $\ldots \ldots \ldots \ldots, 10$

3.2 ISV MELT SETTING OVERLAP CAPABILITY

DEMONSTRATION $\ldots \ldots \ldots \ldots \ldots \ldots \ldots \ldots \ldots \ldots \ldots \ldots \ldots$

3.3 OFF-GAS HANDLING OF VOLATILIZED ${ }^{137} \mathrm{Cs}$ CAPABILITY

DEMONSTRATION ........................ 11

3.4 ISV PRODUCT QUALITY DEMONSTRATION

AT FIELD SCALE ....................... 11

3.5 PUBLIC AND TECHNICAL COMMUNITY ACCEPTANCE $\ldots \ldots .11$

4. EXPERIMENTAL DESIGN AND PROCEDURES $\ldots \ldots \ldots \ldots \ldots \ldots \ldots, 13$

4.1 PIT 1 CHARACTERIZATION $\ldots \ldots \ldots \ldots \ldots \ldots \ldots \ldots \ldots \ldots, 13$

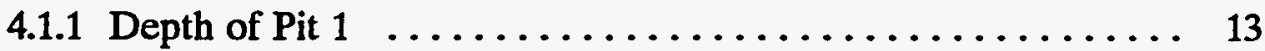

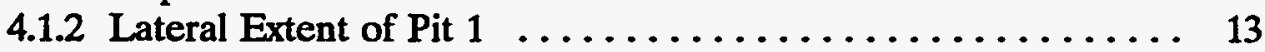

4.1.3 Distribution of Radioactivity Within Pit $1 \ldots \ldots \ldots \ldots \ldots \ldots$

4.1.4 Vertical Distribution of Radioactivity Within

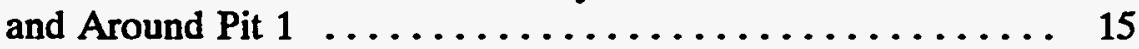

4.1.5 Water Table Elevation Within and Around Pit $1 \ldots \ldots \ldots \ldots$

4.1.6 Bulk Density and Porosity of Pit 1 Fill (Soil) Material ...... 16

4.1.7 Chemical Analyses of Pit 1 Soil and Fill ............... 16

4.1.8 Radiochemical Analyses of Pit 1 Soil and Fill ........... 17

4.1.9 Melt Properties of Pit 1 Soil and Fill $\ldots \ldots \ldots \ldots \ldots \ldots \ldots 17$

4.1.10 Sludge Chemical and Radiochemical Composition ........ 17

4.1.11 Sludge Leach Properties $\ldots \ldots \ldots \ldots \ldots \ldots \ldots \ldots, 18$

4.1.12 Site Preparation for ISV $\ldots \ldots \ldots \ldots \ldots \ldots \ldots \ldots, 18$

4.2 ISV MELTING OPERATIONS $\ldots \ldots \ldots \ldots \ldots \ldots \ldots \ldots \ldots \ldots, 18$

4.2.1 Depth and Lateral Goals ..................... 19

4.2.2 Selection of Melt Additives $\ldots \ldots \ldots \ldots \ldots \ldots \ldots \ldots, 19$

4.2.3 Selection of Melt Tracers .................... 19

4.2.4 Off-Gas Hood Design and Fabrication $\ldots \ldots \ldots \ldots \ldots \ldots .20$

4.2 .5 Off-Gas Hood Filtration System $\ldots \ldots \ldots \ldots \ldots \ldots \ldots \ldots 20$

4.2.6 Off-Gas Monitoring $\ldots \ldots \ldots \ldots \ldots \ldots \ldots \ldots \ldots \ldots \ldots \ldots \ldots \ldots \ldots \ldots \ldots, 21$

4.2.7 Electrode Spacing Selection $\ldots \ldots \ldots \ldots \ldots \ldots \ldots \ldots \ldots, 21$

4.2.8 Melt Depth and Width Monitoring $\ldots \ldots \ldots \ldots \ldots \ldots \ldots, 22$

4.2.9 Melt Temperature Monitoring $\ldots \ldots \ldots \ldots \ldots \ldots \ldots \ldots, 22$

4.2.10 Generator Selection ....................... 23

4.2.11 Off-Gas Hood Demobilization and Storage $\ldots \ldots \ldots \ldots \ldots 23$ 
4.2.12 Melt Visual Monitoring ................. 23

4.3 POSTTEST PRODUCT AND SITE CHARACTERIZATION . . . . . . 24

4.3.1 Product Sampling ...................... 24

4.3.2 Product Chemical and Radiochemical Analyses .......... 25

4.3.3 ISV Product Leaching Characteristics $\ldots \ldots \ldots \ldots \ldots \ldots .25$

4.3.4 In Situ ISV Product Performance ................ 25

4.3.5 Product Mineralogical Characterization $\ldots \ldots \ldots \ldots \ldots \ldots, 26$

4.3.6 Off-Gas Analyses . ....................... 26

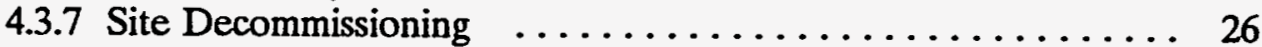

5. EQUIPMENT AND MATERIALS $\ldots \ldots \ldots \ldots \ldots \ldots \ldots \ldots \ldots \ldots \ldots \ldots \ldots$

6. SAMPLING AND ANALYSIS $\ldots \ldots \ldots \ldots \ldots \ldots \ldots \ldots \ldots \ldots \ldots \ldots \ldots \ldots, 28$

6.1 PRETEST SITE CHARACTERIZATION $\ldots \ldots \ldots \ldots \ldots \ldots \ldots \ldots, 28$

6.2 ISV OPERATIONAL MONITORING .................... 29

6.3 POSTTEST PRODUCT AND SITE CHARACTERIZATION $\ldots \ldots .29$

7. DATA MANAGEMENT $\ldots \ldots \ldots \ldots \ldots \ldots \ldots \ldots \ldots \ldots \ldots \ldots \ldots \ldots \ldots \ldots \ldots$

8. DATA ANALYSIS AND INTERPRETATION $\ldots \ldots \ldots \ldots \ldots \ldots \ldots \ldots, 31$

9. HEALTH AND SAFETY PLAN $\ldots \ldots \ldots \ldots \ldots \ldots \ldots \ldots \ldots \ldots \ldots, 32$

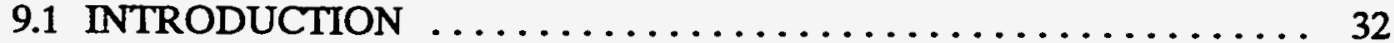

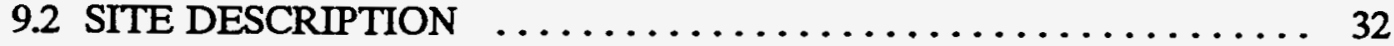

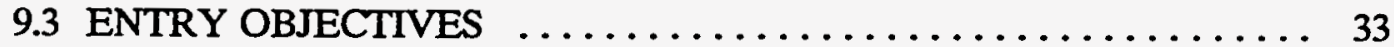

9.4 ON-SITE ORGANIZATION AND COORDINATION $\ldots \ldots \ldots \ldots \ldots, 34$

9.5 LOCAL AGENCY REPRESENTATIVES $\ldots \ldots \ldots \ldots \ldots \ldots \ldots, 34$

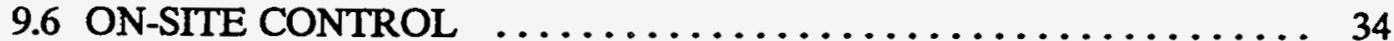

9.7 HAZARDS EVALUATION $\ldots \ldots \ldots \ldots \ldots \ldots \ldots \ldots \ldots \ldots \ldots \ldots \ldots \ldots$

9.8 EMPLOYEE TRAINING $\ldots \ldots \ldots \ldots \ldots \ldots \ldots \ldots \ldots \ldots \ldots, 36$

9.9 PERSONAL PROTECTIVE EQUIPMENT $\ldots \ldots \ldots \ldots \ldots \ldots \ldots, 36$

9.10 MEDICAL SURVEILLANCE $\ldots \ldots \ldots \ldots \ldots \ldots \ldots \ldots \ldots, 38$

9.11 PERSONAL AND ENVIRONMENTAL MONITORING $\ldots \ldots \ldots, 38$

9.12 EMERGENCY RESPONSE PLAN $\ldots \ldots \ldots \ldots \ldots \ldots \ldots \ldots \ldots, 39$

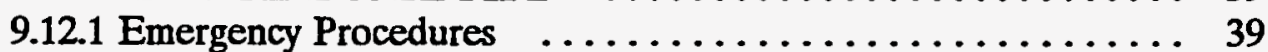

9.12.2 Emergency Escape Route .................. 40

9.12.3 Emergency Contacts .................... 41

9.13 CONFINED-SPACE ENTRY PROCEDURES $\ldots \ldots \ldots \ldots \ldots \ldots \ldots, 41$

9.14 SPILL CONTAINMENT PROGRAM $\ldots \ldots \ldots \ldots \ldots \ldots \ldots \ldots, 41$

9.15 COMMUNICATION PROCEDURES $\ldots \ldots \ldots \ldots \ldots \ldots \ldots \ldots, 41$

9.16 HEALTH AND SAFETY REFERENCES $\ldots \ldots \ldots \ldots \ldots \ldots \ldots, 42$

10. RESIDUALS MANAGEMENT $\ldots \ldots \ldots \ldots \ldots \ldots \ldots \ldots \ldots \ldots \ldots$

11. COMMUNITY RELATIONS PLAN $\ldots \ldots \ldots \ldots \ldots \ldots \ldots \ldots \ldots \ldots, 44$

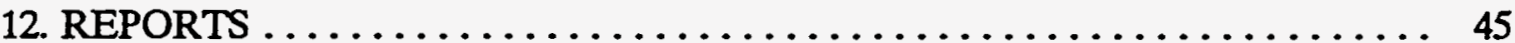


13. SCHEDULE $\ldots \ldots \ldots \ldots \ldots \ldots \ldots \ldots \ldots \ldots \ldots \ldots \ldots \ldots \ldots \ldots \ldots$

14. MANAGEMENT AND STAFFING $\ldots \ldots \ldots \ldots \ldots \ldots \ldots \ldots \ldots \ldots \ldots$

15. BUDGET $\ldots \ldots \ldots \ldots \ldots \ldots \ldots \ldots \ldots \ldots \ldots \ldots \ldots \ldots \ldots \ldots \ldots \ldots$

16. REFERENCES $\ldots \ldots \ldots \ldots \ldots \ldots \ldots \ldots \ldots \ldots \ldots \ldots \ldots \ldots \ldots \ldots \ldots$ 


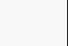




\section{FIGURES}

1. ORNL Waste Area Grouping 7, which contains the seven seepage pits and trenches, showing location of the pit 1 treatability study site. . . . . . . . .

2. ORNL seepage pit 1 dimensions showing the paving and grading plan for covering, taken from Energy Systems Engineering drawing C3D20929A001 (1981). Scale is indicated by the 100 -ft administrative grid tick marks. . . . . . 3

3. Photograph of ORNL seepage pit 1 in 1955 showing the roof covering. . . . . 4

4. View of ORNL seepage pit 1 with asphalt cap in December $1988 . \ldots \ldots \ldots$. . 5

5. Schematic illustration of the in situ vitrification process applied to an ORNL seepage trench. ........................... 7

6. Disposition of materials during in situ vitrification processing. $\ldots \ldots \ldots \ldots \ldots$

7. Volatilization of ${ }^{137} \mathrm{Cs}$ from soil:limestone mixtures heated to $1200^{\circ} \mathrm{C}$ with amendments of chloride species. ..................... 8

8. Penetration point grid in and around ORNL seepage pit 1 showing maximum

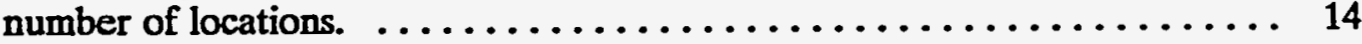

9. Survey of gamma dose rates $(\mu \mathrm{R} / \mathrm{h})$ at $1 \mathrm{~m}$ above the surface and at the ground surface at ORNL Pit 1 (from Carrier et al. 1989). ............... 33

10. Schedule for the ORNL pit 1 ISV treatability study and supported WAG 7 closure activities. 



\section{EXECUTIVE SUMMARY}

A treatability study is described that encompasses the application of in situ vitrification (ISV) to at least two segments of Oak Ridge National Laboratory (ORNL) seepage pit 1 by the end of fiscal year (FY) 1995. This treatability study will support an Interim Record of Decision (IROD) or removal action for closure of one or more of the seepage pits and trenches in FY 1996. The Remedial Investigation/Feasibility Study for Waste Area Grouping (WAG) 7, which contains these seven seepage pits and trenches, will probably begin in FY 1994, leading to a probable ROD for all of WAG 7 in FY 1997, with a probable completion of closure in FY 1999. This treatability study will establish the field-scale technical performance of ISV for (1) attaining the required depth, nominally $15 \mathrm{ft}$, to incorporate source contamination within and beneath the pits; (2) demonstrating field capability for the overlapping melt settings that are necessary to achieve fused melt segments; (3) demonstrating off-gas handling technology for accommodating and minimizing the volatilization of ${ }^{137} \mathrm{Cs}$; (4) demonstrating adequate site characterization techniques to predict ISV melting kinetics, processing temperatures, and product durability; and (5) promoting public acceptance of ISV technology by demonstrating its safety, implementability, site impacts, and air emissions and by coordinating the treatability study within the regulatory closure process. The format and content of this treatability study work plan follows the U.S. Environmental Protection Agency document, Guide for conducting treatability studies under CERCLA Interim Final, EPA/540/2-89/058, 1989.

In situ vitrification is a promising technology that could be applied to the pits and trenches on the Oak Ridge Reservation (other technologies include grouting and ground densification). ISV, developed and patented for the U. S. Department of Energy by Battelle Pacific Northwest Laboratory (PNL), involves placing electrodes in an array above a contaminated volume of soil, applying power to the electrodes, and melting the entire mass of soil into a chemically homogeneous and durable glassy-to-microcrystalline waste form (Handbook vitrification technologies for treatment of hazardous and radioactive waste, EPA/625/R-92/002, U.S. Environmental Protection Agency, 1992). The array of vertical electrodes is inserted into the soil to a nominal depth (about two electrode diameters) above the waste site, and, since dry soil is not electrically conductive, a conductive material (typically glass frit and graphite flake) is placed in paths between the electrodes to act as the initial resistive heating element. The soil-melting process is initiated when an electric potential applied to the electrodes establishes a current in the path, in turn heating the path and the surrounding soil to temperatures above the melting point. Once molten, the soil becomes electrically conductive. Power to the melt is controlled as the process continues and the molten soil mass grows downward and outward (typically maintaining temperatures between $1400^{\circ} \mathrm{C}$ and $2000^{\circ} \mathrm{C}$ ). The melt dissolves and/or incorporates radionuclides and nonvolatile hazardous elements, such as heavy metals, and destroys organic components by pyrolysis. Semivolatile metals are largely retained in the melt, but the small quantity of material that does escape from the melt is captured and treated. The fate and disposition of various materials during ISV processing has been determined in previous studies; organics are pyrolyzed and combusted, metals are melted and, because of their density, sink to the bottom of the ISV melt. Most other inorganic components are incorporated into the ISV glassy or crystalline product. 
The initial step of this treatability study will be to gather the required site characterization data about pit 1 so that the in situ vitrification can be effectively and safely planned. This characterization phase is critical, not only for the ISV of pit 1, but, more importantly, as a demonstration of what information is needed for ISV planning and how it can be gathered efficiently for the remedial investigation of all the ORNL seepage pits and trenches. The characterization techniques and information should also support alternative remediation techniques in WAG 7, and the characterization approach should provide a useful method for other site characterization activities. Using in situ radioactivity logging within pipes driven into pit 1 , the three-dimensional distribution of radioactive contamination in the pit 1 environs will be determined so that depth and lateral targets for ISV can be set. Additionally a variety of other pit 1 characteristics, which will affect vitrification operations, will be determined, including its bulk density, chemical composition, presence and amounts of groundwater, and ambient contaminant leach properties.

The second phase of this treatability study will be the field ISV operations at pit 1 employing at least two settings.to achieve overlapping and fused melts. Such field operations are likely to require 6 to 8 weeks (including mobilization and demobilization of ISV equipment) to complete and should proceed smoothly, based on the successful completion of site characterization. The ISV melting operations will be performed by PNL personnel and will follow their established and documented safe operating procedures and a test plan for operation of either the pilot-scale or large-scale equipment. However, considerable development or modification of ISV off-gas handling equipment will need to be performed to meet the objectives of this pit 1 treatability study.

Following termination of ISV melting operations at pit 1 and demobilization of portable ISV equipment and the off-gas hood, posttest characterization activities will begin. Such characterization will focus on process performance and product quality. An evaluation will be performed to determine the level of success in meeting all project objectives. A variety of characteristics will be assessed in this evaluation. Product will be characterized for its elemental, radionuclide, and mineralogical composition; its performance in several leaching tests will be determined for assessment of field waste form behavior and comparison with other nuclear waste glass compositions. Monitoring of groundwater quality in the pit 1 environs will continue to provide actual in situ field performance of the ISV waste form. Mass balances and distribution in off-gas system components for radionuclides will be determined, and melt retention factors for all radionuclides will be calculated so that radiological applications of ISV for all the ORNL seepage pits and trenches can be assessed. 


\section{PROJECT DESCRIPTION}

A treatability study is described that encompasses the application of in situ vitrification (ISV) to at least two segments of Oak Ridge National Laboratory (ORNL) seepage pit 1 by the end of fiscal year (FY) 1995. This treatability study will support an Interim Record of Decision (IROD) or removal action for closure of one or more of the seepage pits and trenches in early FY 1996. The Remedial Investigation/Feasibility Study (RI/FS) for Waste Area Grouping (WAG) 7, which contains these seven seepage pits and trenches, will probably begin in FY 1994, leading to a probable ROD for all of WAG 7 in FY 1997, with a probable completion of closure in FY 1999. This treatability study will establish the field-scale technical performance of ISV for (1) attaining the required depth, nominally $15 \mathrm{ft}$, to incorporate source contamination within and beneath the pits; (2) demonstrating field procedures for overlapping melt settings that are necessary to achieve fused melt segments; (3) demonstrating off-gas handling technology for accommodating and minimizing the volatilization of ${ }^{137} \mathrm{Cs}$; (4) demonstrating adequate site characterization techniques to predict ISV melting kinetics, processing temperatures, and product durability; and (5) promoting public acceptance of ISV technology by demonstrating its safety, implementability, site impacts, and air emissions and by coordinating the treatability study within the regulatory closure process. The format and content of this treatability study work plan follows regulatory agency guidance (U.S. EPA 1989).

ORNL contains many soil sites that have been significantly contaminated with mixed fission products and transuranic isotopes. From 1951 through 1966 ORNL disposed of more than a million curies (Table 1) via liquid waste seepage into seven shallow pits and trenches which are contained in WAG 7 (Fig. 1). Presently the pits and trenches are covered with asphalt and require regular maintenance. However, this inventory of radioactivity is situated within $20 \mathrm{ft}$ of the water table and in places only $100 \mathrm{ft}$ from perennial surface streams. The present and potential mobility of radionuclides, particularly ${ }^{90} \mathrm{Sr}$, into shallow groundwater and streams represents one of the most significant long-term risks posed by ORNL waste management units. The levels of radioactivity in the ORNL seepage pits and trenches would restrict any direct contact by remediation workers or machine operators. Radiation fields at contact with exhumed waste would probably fall in the range of $200-1000 \mathrm{R} / \mathrm{hr}$. In addition to such probably lethal radiation fields, for which shielding may provide some relief, containment of contamination would be extremely important to prevent any ingestion or inhalation of contamination by operating personnel. Any exhumation approach entails a large risk for environmental releases because of the proximity to surface water and the generally wet climate of the area. Such hazards, coupled with the lack of any credible alternative disposal site or method for exhumed waste, have focused consideration on in situ stabilization and closure techniques, particularly for high-radiation-hazard waste management units like the ORNL seepage pits and trenches.

Pit 1 was constructed in August 1951 by digging a 30 by $115 \mathrm{ft}$ trench (Fig. 2) into weathered shale residuum to a maximum nominal depth of $15 \mathrm{ft}$. During the following 3 months, pit 1 is estimated to have received about $389 \mathrm{Ci}$ of mixed fission products, $200 \mathrm{~kg}$ of depleted uranium $\left(0.0678 \mathrm{Ci}\right.$ if $\left.{ }^{238} \mathrm{U}\right)$, and $266 \mathrm{mg}$ of plutonium $\left(0.017 \mathrm{Ci}\right.$ if $\left.{ }^{239} \mathrm{Pu}\right)$, as sludge suspended in highly alkaline liquid waste (approximately 123,000 gal). The exact mixture of fission product isotopes was not reported in the disposal records for pit 1 . If it is assumed 


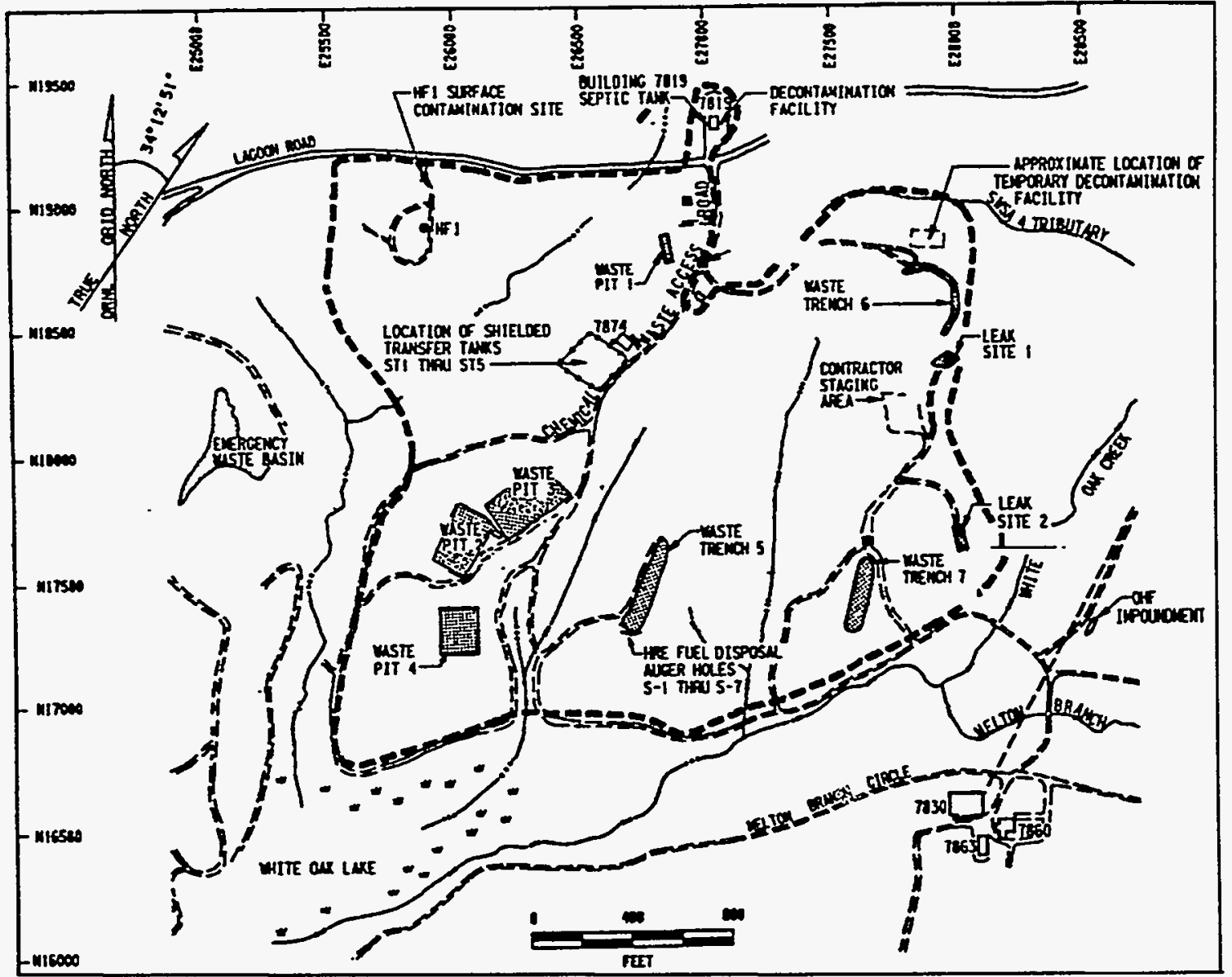

Fig. 1. ORNL Waste Area Grouping 7, which contains the seven seepage pits and trenches, showing location of the pit 1 treatability study site.

that the pit 1 fission product waste is similar to the sludge from ORNL pit 2, which was analyzed and used in the 1991 radioactive ISV test (Spalding et al. 1992), then $80.2 \%$ of the present activity would be composed of ${ }^{137} \mathrm{Cs}$ and $19.8 \%$ would be composed of ${ }^{90} \mathrm{Sr}$ while ${ }^{106} \mathrm{Ru}$, with its 367-day half-life, would have decayed completly in the 42 years since pit 1 use. Disposal records estimated that total beta emitters disposed in pit 1 were $60 \%{ }^{137} \mathrm{Cs}$ and $40 \%$ ${ }^{106} \mathrm{Ru}$. If it is assumed that the recorded beta activity of ${ }^{n 137} \mathrm{Cs}^{n}$ was actually a mixture of ${ }^{137} \mathrm{Cs}$ 


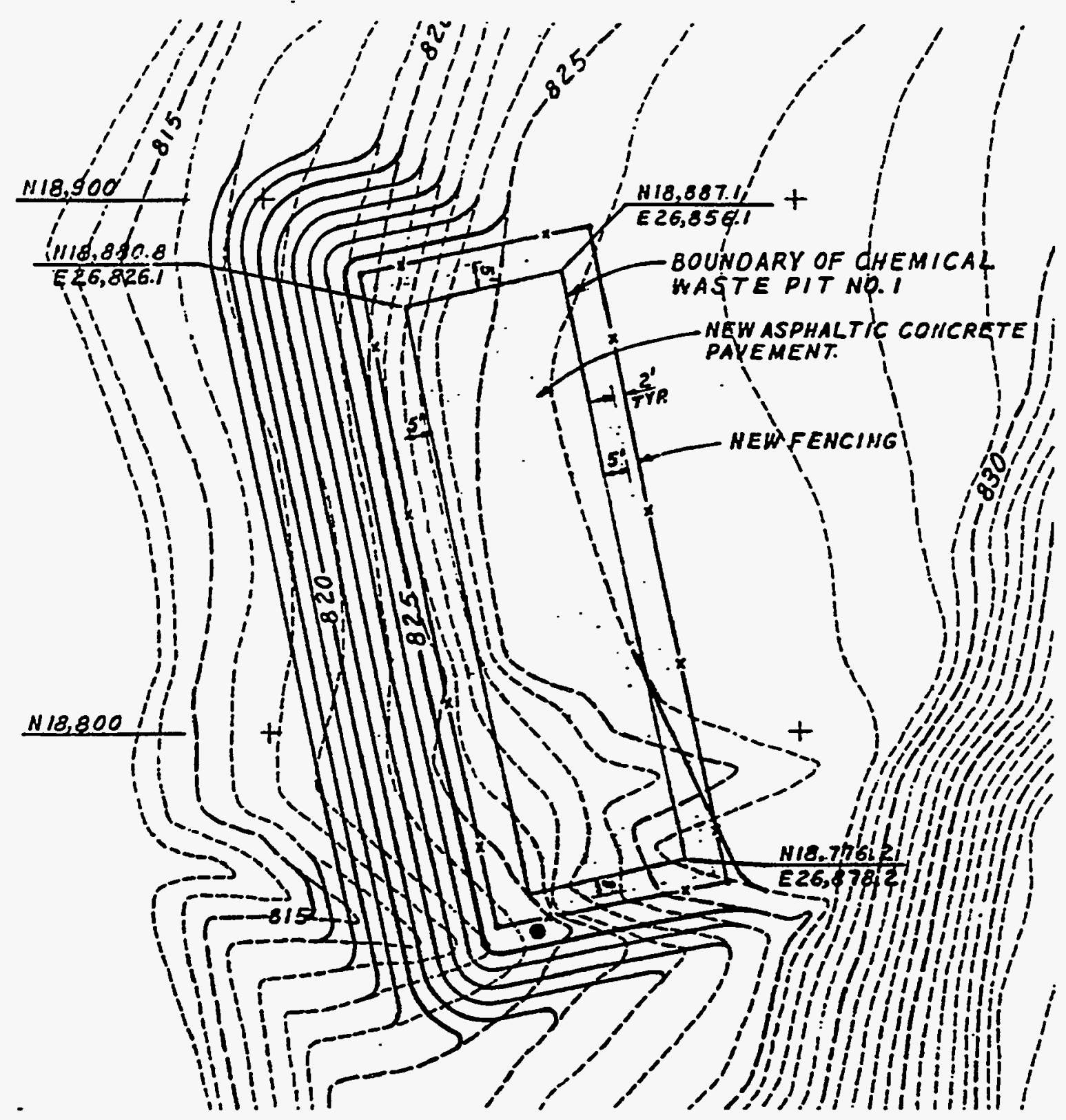

Fig 2 ORNL seepage pit 1 dimensions showing the paving and grading plan for covering, taken from Energy Systems Engineering drawing C3D20929A001 (1981). Scale is indicated by the $100-\mathrm{ft}$ administrative grid tick marks.

and ${ }^{90} \mathrm{Sr}$, as found for the pit 2 sludge, and correcting for decay to 1993 , then the estimates of ${ }^{137} \mathrm{Cs}$ and ${ }^{90} \mathrm{Sr}$ presently in pit 1 would be 71.0 and $17.5 \mathrm{Ci}$, respectively. However, these must be viewed as working estimates based on the number of assumptions and the disposal record quality. Thus, a significant part of the present treatability study will center on a better characterization of the present pit 1 radioisotopic inventory. This pit was a proof-of-principle 
Table 1. Summary characteristics of ORNL seepage pits and trenches in Waste Area Grouping 7.

\begin{tabular}{|c|c|c|c|c|c|}
\hline Waste Unit & $\begin{array}{c}\text { Size } \\
(1 \times w \times d-f t)\end{array}$ & $\begin{array}{l}\text { Dates } \\
\text { Used }\end{array}$ & $\begin{array}{c}\text { Volume } \\
\text { Disposed } \\
\text { (gal) }\end{array}$ & $\begin{array}{l}\text { Activity" } \\
\text { (Ci) }\end{array}$ & Isotopes \\
\hline Pit $1^{b}$ & $115 \times 30 \times 10+$ & 1951 (leak) & 120,000 & 389 & $\mathrm{Cs}, \mathrm{Sr}, \mathrm{Ru}^{\mathrm{c}}$ \\
\hline Pits 2, 3, 4 & $200 \times 100 \times 15$ & 1952-1962 & $24,000,000$ & 480,000 & $\mathrm{Cs}, \mathrm{Sr}, \mathrm{Ru}$ \\
\hline $\begin{array}{l}\text { Pit } 4 \text { only, } \\
\text { additional } \\
\text { disposal }\end{array}$ & $200 \times 100 \times 15$ & 1956-1976 & $9,000 /$ week & undetermined & $\begin{array}{l}\text { Sludge from } \\
\text { Process Water } \\
\text { Treatment Plant }\end{array}$ \\
\hline Trench 5 & $300 \times 10 \times 15$ & $1960-1966$ & $9,500,000$ & 308,500 & $\mathrm{Cs}, \mathrm{Sr}, \mathrm{TRU}$ \\
\hline Trench 6 & $450 \times 10 \times 15$ & 1961 (leak) & 130,000 & 1,335 & $\mathrm{Cs}, \mathrm{Sr}, \mathrm{TRU}$ \\
\hline Trench 7 & $200 \times 10 \times 15$ & $1962-1966$ & $9,500,000$ & 283,900 & $\mathrm{Cs}, \mathrm{Sr}, \mathrm{TRU}$ \\
\hline
\end{tabular}

- Activity at the time of disposal as stated in operations records exclusive of $U$ and transuranic (TRU) elements.

b Pit 1 also received drain discharges from a decontamination building from 1962-1976, but there was probably no significant change in radionuclide inventory.

'Exact radioisotopic composition is not available in disposal records. See text for discussion and assumptions.

Source: Spalding 1987.

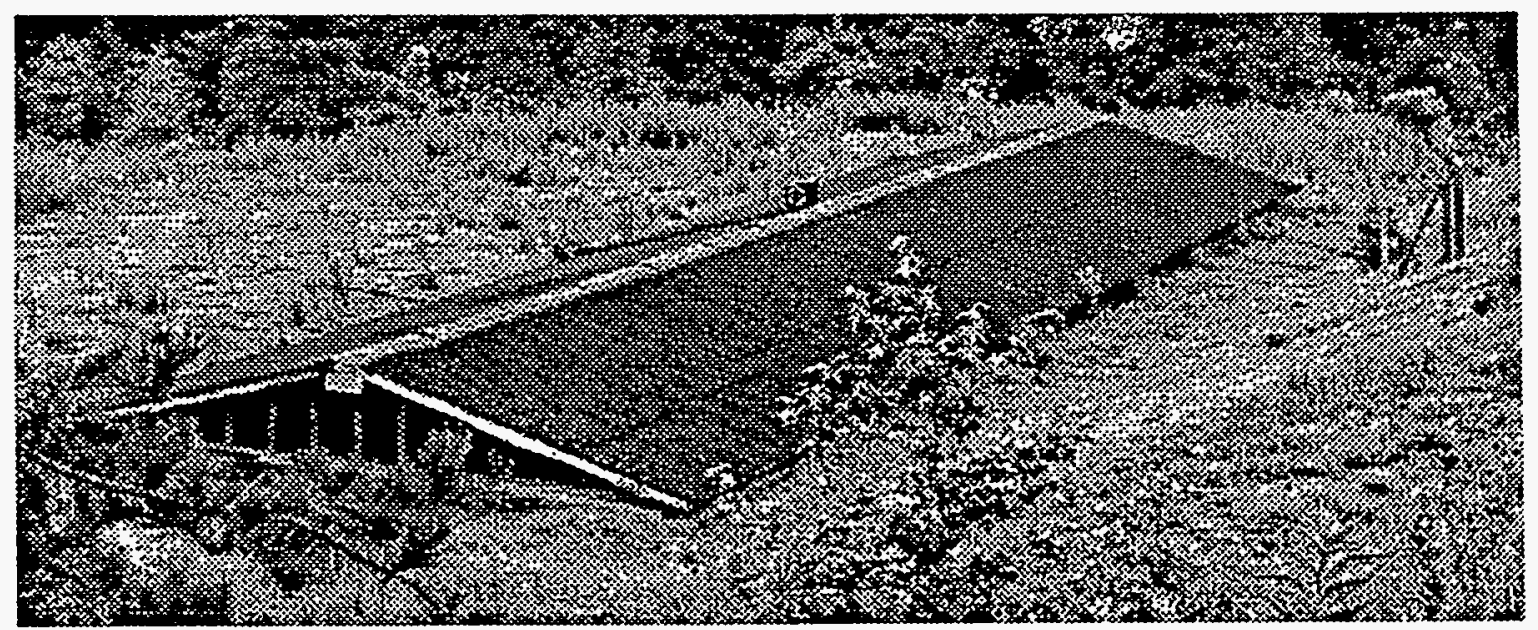

Fig. 3. Photograph of ORNL seepage pit 1 in 1955 showing the roof covering.

operation, and, although it leaked into a nearby drainage, a larger pit 2 was constructed in 1952 , becoming the operational disposal unit for liquid radioactive waste at ORNL. Although not used for routine liquid waste disposal after 1951, pit 1 received discharges via a buried pipeline from drains in the nearby decontamination building (7819) between 1962 and 1970. 


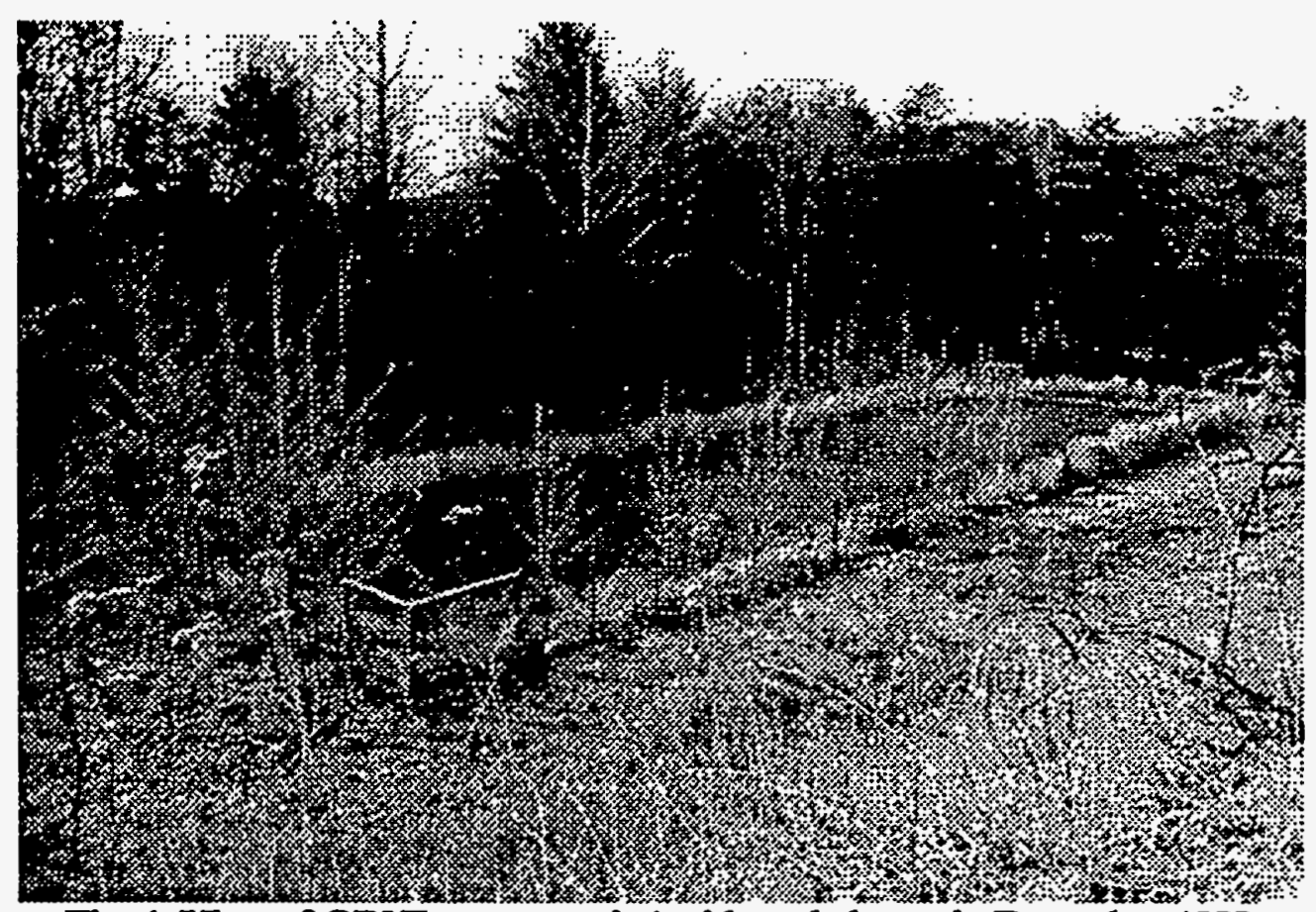

Fig. 4. View of ORNL seepage pit 1 with asphalt cap in December 1988

These discharges of acids, soaps, and chelating agents were not measured, but this contacthandled equipment decontamination facility probably did not add significantly to the inventory of radioactivity in pit 1 . During this and previous operations, pit 1 was spanned by a wooden roof with asphalt-coated corrugated metal sheeting to prevent infiltration of precipitation (Fig. 3). In 1981, the pit was filled with soil and capped with asphaltic concrete. Since that time the pavement has been resealed occasionally with various asphaltic coatings and the site surrounded by a 4-ft-high barbed-wire fence with appropriate hazard warning signs (Fig. 4). 


\section{REMEDIAL TECHNOLOGY DESCRIPTION}

In situ vitrification is a promising technology that could be applied to the pits and trenches on the Oak Ridge Reservation (other technologies include grouting and ground densification). ISV, developed and patented for the U. S. Department of Energy (DOE) by Battelle Pacific Northwest Laboratory (PNL), involves placing electrodes in an array above a contaminated volume of soil, applying power to the electrodes, and melting the entire mass of soil into a chemically homogeneous and durable glassy-to-microcrystalline waste form (U.S. EPA 1992). Figure 5 depicts the ISV processing sequence as applied to a liquid waste disposal seepage trench. An array of vertical electrodes is inserted into the soil to a nominal depth (about two electrode diameters) above the waste site, and, since dry soil is not electrically conductive, a conductive material (typically glass frit and graphite flake) is placed in paths between the electrodes to act as a resistive heating element. The soil-melting process is initiated when an electric potential applied to the electrodes establishes a current in the path, in turn heating the path and the surrounding soil to temperatures above the melting point of soil. Once molten, the soil becomes electrically conductive. Power to the melt is controlled as the process continues and the molten soil mass grows downward and outward (typically maintaining temperatures between $1400^{\circ} \mathrm{C}$ and $2000^{\circ} \mathrm{C}$ ). The melt dissolves and/or incorporates radionuclides and nonvolatile hazardous elements, such as heavy metals, and destroys organic components by pyrolysis. Semivolatile metals are largely retained in the melt, but the small quantity of material that does escape from the melt is captured and treated. The fate and disposition of various materials during ISV processing is depicted in Fig. 6.

A hood placed over the area being vitrified confines the gases released from the melt and directs them to an off-gas treatment system that uses a combination of wet-scrubbing and dryfiltering. Power to the melt is maintained until the desired depth is obtained and the soil and its contents are melted. Since the conductivity of the melt increases as the melt volume increases, the ISV power supply is equipped with a series of voltage taps to maintain a constant power level to the melt. Upon cooling, the molten soil solidifies into a vitrified mass resembling natural obsidian in appearance and, most importantly, in durability, with a leach resistance approaching that of high-quality laboratory glassware (Buelt et al. 1987; Callow et al. 1991). In the recent ORNL pilot-scale test (Spalding et al. 1992), significant crystallization of the melt material occurred during cooling. However, this crystallization did not result in any decrease in leach resistance of the ISV product.

The electrode feed system currently used during ISV grew out of a need to remotely control the vertical position of the electrodes. Previously, ISV technology used fixed or preplaced electrodes at the site to be vitrified; the electrodes were inserted into casings that were pounded or drilled to the target treatment depth. The primary driver for the development and implementation of the electrode feeding technology was the need to improve the performance of the ISV when processing a site containing buried metal (Farnsworth et al. 1990). Metal inclusions melt when they are contacted by the molten soil region. Molten metal is more dense than molten soil and stratifies at the bottom of the melt, thus creating the possibility of an electrical short circuit between the electrodes. It is impossible to continue ISV melting after an electrical short circuit when using fixed electrodes. 


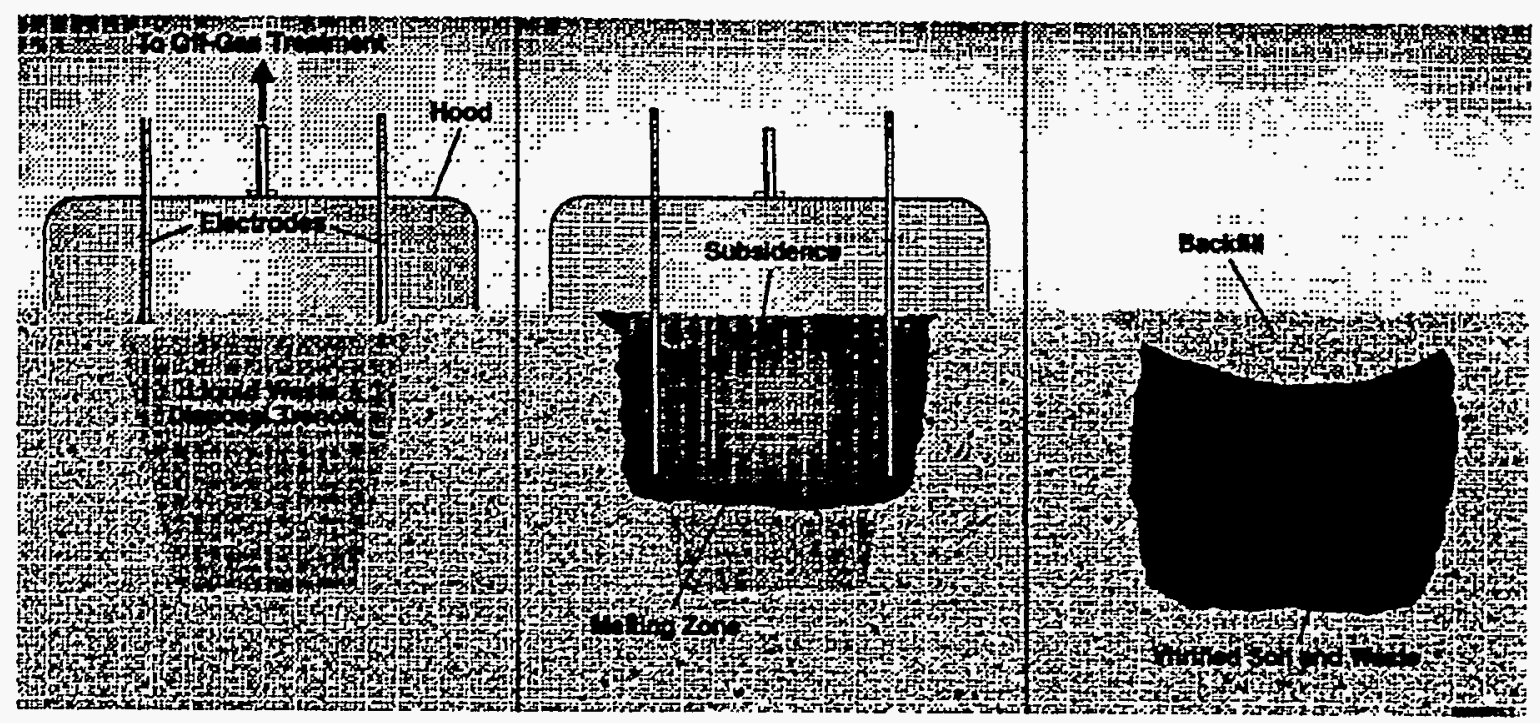

Fig. 5. Schematic illustration of the in situ vitrification process applied to an ORNL seepage trench.

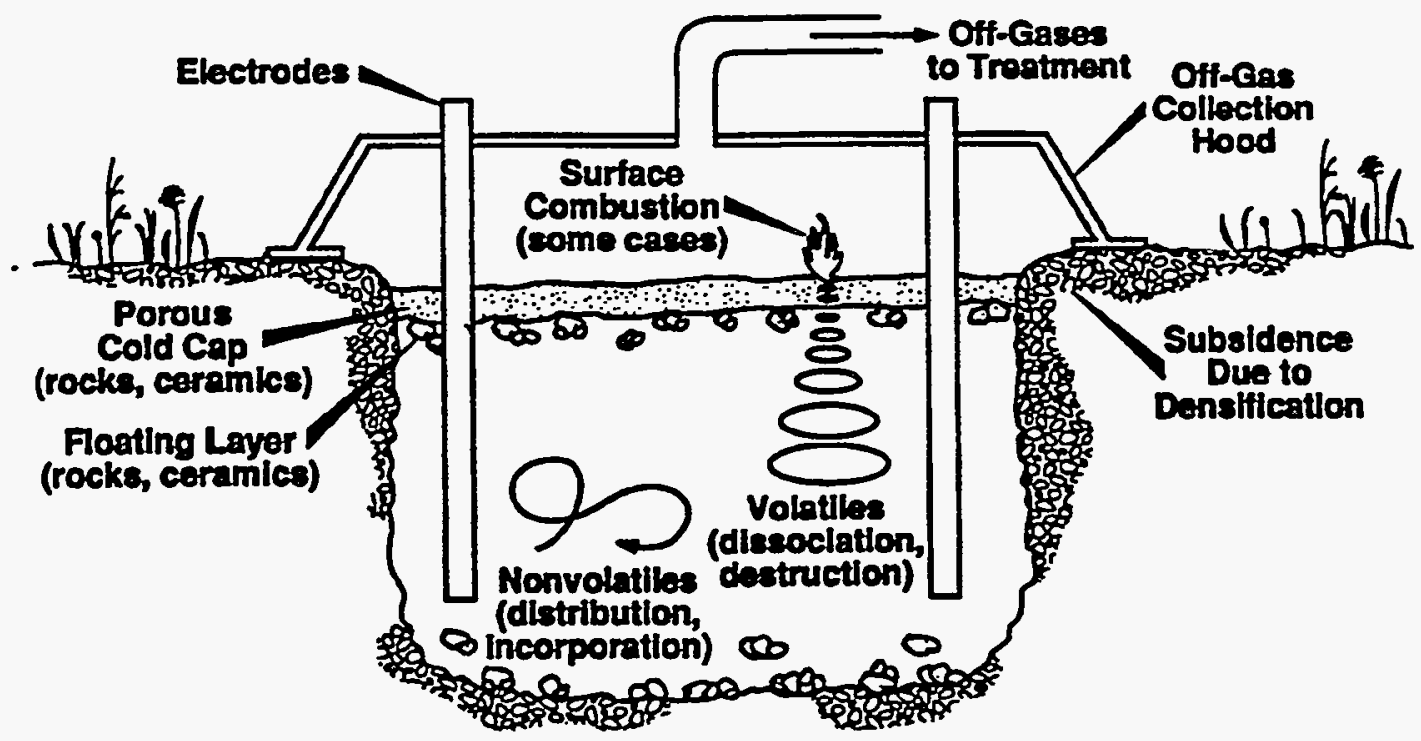

Fig. 6. Disposition of materials during in situ vitrification processing.

During the ISV process, the electrode feed system is used to control the vertical position of the electrodes in the melt. The electrodes can be fed in either a passive or active mode. In the passive mode they are allowed to feed downward by gravity, constantly resting on the bottom of the melt. In the active mode they can be retracted, held, or advanced, which is necessary whenever a molten metal pool forms during the processing of materials containing 
scrap metal objects. Raising the electrodes out of the metal pool eliminates the possibility of an electrical short circuit.

The electrode feed system has been successfully implemented on the engineering- and pilot-scale ISV system and was successfully used during the 1991 ORNL radioactive field test. In July 1991 the electrode feed system was successfully demonstrated with the large-scale system and has been recommended to replace the fixed electrode technique as the new baseline electrode placement technology for all future full-scale ISV demonstrations and remediation campaigns at DOE and commercial sites. While the metals content of the ORNL pits and trenches is minimal and would not present a problem for the fixed electrode technique, there are other substantial advantages to implementing the electrode feed system. Compared with the previous baseline ISV technology, the electrode feed system greatly reduces equipment costs, generation of secondary wastes, risk of electrode failure by oxidation, setup time per setting, and exposure of personnel and equipment to environmental hazards, while at the same time increasing the flexibility of the ISV process. Electrode feeding also avoids the necessity of intruding into contaminated soil or waste prior to ISV.

ORNL has completed two demonstrations of ISV for application to radioactively contaminated soil sites like those in WAG 7. In 1987, a nonradioactive field demonstration was completed using chemical amendments for tracing the radioisotopes that would be encountered in actual application to pits and trenches (Spalding and Jacobs 1989). That demonstration showed encouraging retention of cesium and strontium within the ISV melt,

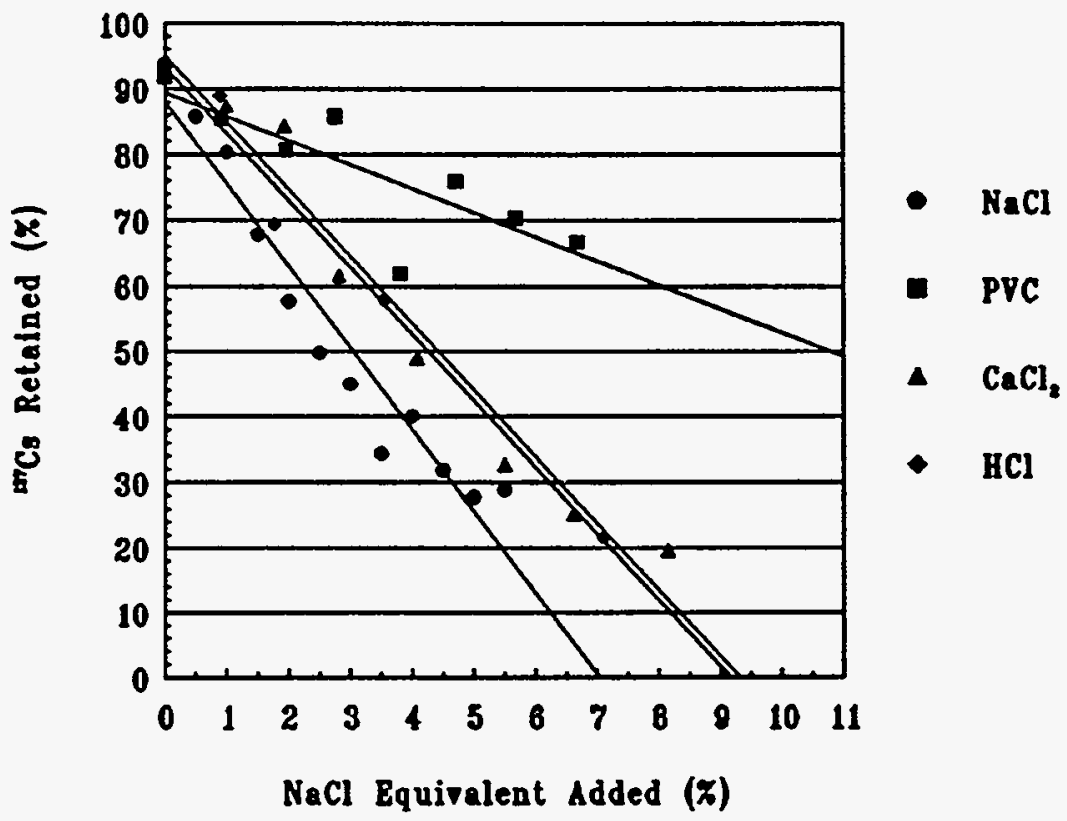

Fig. 7. Volatilization of ${ }^{137} \mathrm{Cs}$ from soillimestone mixtures heated to $1200^{\circ} \mathrm{C}$ with amendments of chloride species. 
good melt mixing, good quality for the product formed from indigenous soil and limestone materials, and ISV compatibility with the geologic features in WAG 7. However, the demonstration raised concern about the present ISV capability to handle even a potentially small amount of volatilization of ${ }^{137} \mathrm{Cs}$, which might occur in actual ISV application.

In 1991, a radioactive demonstration was completed (Spalding et al. 1992), also at the pilot-scale, using a sample of sludge from one of the seepage pits that contained a limited but measured amount of radioactivity $\left(10 \mathrm{mCi}\right.$ of $\left.{ }^{137} \mathrm{Cs}\right)$. This recent demonstration established an off-gas processing technique to handle ${ }^{137} \mathrm{Cs}$ volatilization using a high-temperature, highefficiency particulate air (HEPA) prefilter placed in the off-gas collection system prior to the off-gas scrubbing and quenching system. This prefilter removed all detectable ${ }^{137} \mathrm{Cs}$ from the off-gas and thus demonstrated a method for avoiding radiation exposure to ISV operators from what otherwise would be a buildup of ${ }^{137} \mathrm{Cs}$ in the off-gas handling equipment. However, this demonstration experienced a volatilization of $2.4 \%$ of the ${ }^{137} \mathrm{Cs}$ inventory, unlike the 1987 demonstration where only $0.12 \%$ of the cesium amendment was volatilized. The prefilter was also found to contain at or below detection limits for other radioisotopes: $<0.0001 \%$ of the ${ }^{90} \mathrm{Sr},<0.007 \%$ of the ${ }^{241} \mathrm{Am},<0.006 \%$ of the ${ }^{239,240} \mathrm{Pu}$, and $0.17 \%$ of ${ }^{60} \mathrm{Co}$ in the melt inventory. A more accurate estimate of transuranic isotope capture on the prefilter was obtained from the analyses of $\mathrm{Ce}, \mathrm{La}$, and $\mathrm{Nd}$ tracers also used in the test; only $0.0005 \%$ of the added amounts of these tracers were found on the prefilter. The increased volatilization of ${ }^{137} \mathrm{Cs}$ in the 1991 demonstration is thought to be caused by chloride-enhanced volatilization of ${ }^{137} \mathrm{Cs}$; the source of chloride was either (1) the polyvinylchloride (PVC) pipe used for access to emplace the radioactive sludge immediately prior to ISV or (2) possibly elevated levels of chloride in the soil, rock, or pore water at the 1991 site. Subsequent laboratory investigations have shown that low chloride amendments ( $<2 \%$ by weight) to crucible melts, whether added as sodium chloride, PVC, or hydrochloric acid, result in markedly enhanced volatilization of ${ }^{137} \mathrm{Cs}$ during heating (Fig. 7). Recent laboratory crucible melts have identified many elements and chemical species that can be present in ISV melts without affecting volatilization of ${ }^{137} \mathrm{Cs}$; these species include fluorides, phosphates, nitrates, sulfates, carbonates, polystyrene, graphite, molybdenum, stainless steel (both 316 and 304), iron, strontium, sodium, lithium, potassium, and cesium. However, other factors, such as in situ steam stripping by the boiling water removed during ISV, may also have contributed to the significant volatilization of the ${ }^{137} \mathrm{Cs}$. Nonetheless, the 1991 demonstration established (1) the feasibility of ISV using the new electrode feed technique, which eliminates the need to place electrodes into contaminated material prior to ISV; (2) the applicability to sites where dolomite, instead of limestone, was used as a trench backfill; (3) the applicability of several geophysical techniques for nondestructive monitoring of melt progress; and (4) the effectiveness of HEPA filtration for complete removal of any volatilized ${ }^{137} \mathrm{Cs}$. 


\section{TEST OBJECTIVES}

Before a decision can be made about whether to implement ISV for stabilization and closure of ORNL seepage pits and trenches, several technical issues must be resolved. These issues dictated the objectives of this treatability study and are listed in order of priority. Although the objectives are obviously interrelated and inseparable, they are addressed in this order where possible, in case resources, time, or safety considerations impinge on the project's capability to completely address all objectives. Completion of all objectives should resolve all field-scale issues related to implementation of ISV for the ORNL seepage pits and trenches. Other objectives may be added to help resolve technical issues relative to ISV at other sites or for other waste types if, and only if, these can be accommodated without any compromise to this treatability study's objectives.

\subsection{ISV MELT DEPTH CAPABIITY DEMONSTRATION}

At present it has not been established that ISV can attain the depth of $15 \mathrm{ft}$ that is required to reach the bottom of trenches and beneath to stabilize undisturbed soil contaminated by transported radionuclides in the WAG 7 geologic setting. Although a maximum depth of ISV of $18 \mathrm{ft}$ has been demonstrated at other sites, this maximum depth does not factor in the geologic, hydrologic, and geometric conditions of the ORNL seepage pits and trenches. For example, during the pilot-scale demonstration in 1987, it was found that the melt tended to grow horizontally, following a path of least resistance into the less densely packed materials used to backfill the trench. Although the melting of this scale-model seepage trench reached its target depth of $9 \mathrm{ft}$, the ability to attain a $15 \mathrm{ft}$ melt depth at ORNL has not been demonstrated. The preference for melting into low density backfill needs to be overcome so that downward melting into the contaminated, higher-density, and undisturbed soil can be ensured. The depth objective of this treatability study will be the actual bottom of pit 1 , including significant contaminated soil beneath the pit-soil formation contact. The depth goal of $15 \mathrm{ft}$ below starting ground surface will be pursued, even if the pit proves to be less deep, unless geologic conditions prohibit or lateral ISV melt body growth within the pit exceeds off-gas hood dimensions.

\section{ISV MELT SETTING OVERLAP CAPABILTTY DEMONSTRATION}

Due to their size and areal extent, all of the seepage pits and trenches will require multiple melt settings to complete vitrification of their source material and contaminated soil. The ability to overlap melts sufficiently to ensure complete treatment between settings needs to be established for the particular geologic and geometric characteristics of the contaminated pits and trenches. In addition, the ability to move a contaminated off-gas hood and establish

a second array of electrodes to produce an overlapping and fused melt in a contaminated environment needs to be demonstrated. 


\section{OFF-GAS HANDLING OF VOLATILIZED ${ }^{137} \mathrm{Cs}$ CAPABILITY DEMONSTRATION}

A more practical design at the operational field scale for the off-gas HEPA prefilter technique needs to be developed and demonstrated. One conceptual design of such a filtering technique would place a HEPA prefilter within the off-gas containment hood at a position where it could be dropped into the melt near the end of the run after ${ }^{137} \mathrm{Cs}$ volatilization had subsided. The 1991 demonstration clearly established that ${ }^{137} \mathrm{Cs}$ volatilization occurred predominantly when the melt initially reached the depth where the contaminated sludge had been positioned. Thus, near the end of ISV melting, rates of volatilization would be minimal and the prefilter, containing the ${ }^{137} \mathrm{Cs}$ volatilized earlier in the run, could be incorporated back into the melt. Alternatively, a rolling prefilter, where the active surface is slowly and continually renewed, could be employed with the spent filter fabric directed into the melt. However, present off-gas containment hoods would require significant modification to accomplish either of these capabilities. Based on the 1991 demonstration's findings that $2.4 \%$ of the ${ }^{137} \mathrm{Cs}$ inventory volatilized, it would be expected that about $1.2 \mathrm{Ci}$ of ${ }^{137} \mathrm{Cs}$ would be trapped on a prefilter from one melt setting in ORNL pit 1, assuming an inventory of $50 \mathrm{Ci}$ (decay corrected to present) of ${ }^{137} \mathrm{Cs}$ per setting (i.e., about one quarter of the pit). Or, the prefilter could be incorporated into the melt at the second setting. In addition, recent investigations have shown the potential for a layer of porous/floating alumina beads on the ISV melt to function as a thermal barrier and thus as a potential condensing or filtering layer for any volatilized ${ }^{137} \mathrm{Cs}$; such materials may be included in one or more of the melt settings at pit 1 . Whatever the conceptual approach, the effectiveness, safety, and reliability need to be demonstrated at the field scale. Off-gas released from the ISV processing trailer will be monitored and reported in compliance with 40 CFR 61, subpart H, National Emission Standards for Emissions of Radionuclides Other Than Radon From Department of Energy Facilities.

\subsection{ISV PRODUCT QUALITY DEMONSTRATION AT FIELD SCALE}

Product quality and its field performance need to be demonstrated to ensure that the benefits of ISV are established adequately to support its implementation for closure of the ORNL seepage pits and trenches. There presently exists a large amount of information about the leach resistance of various vitrified materials. Although data gathered from laboratory tests support many models of field performance, many scale-related factors remain unaddressed. For example, if transient perched water contacts a monolithic ISV product in the field, prediction of site performance is presently difficult given uncertainties of surface area and melt edge effects. Thus, as part of the treatability study, in addition to laboratory measurements of ISV product quality as obtained in the 1991 demonstration (Spalding et al. 1992), the field-produced waste form will be monitored in situ after ISV to determine its leaching characteristics and performance in the field. Comparisons to untreated regions of pit 1 or other seepage pits will be established to aid in site performance assessment.

\subsection{PUBLIC AND TECHNICAL COMMUNITY ACCEPTANCE}

Public and technical community understanding and acceptance can be established through both public distribution of test information and regulatory agency review and involvement in test planning and analysis. It is recognized that a well documented and fully demonstrated 
treatability study will accelerate and facilitate implementation of a ROD for WAG 7. In addition to the seepage pits and trenches, WAG 7 contains other waste management units that may not be amenable to ISV, including an inactive decontamination building, contaminated streambeds and peripheral soil, and near-surface contaminated grout sheets from the initial ORNL hydrofracture test site. ISV is presently being considered only for the major radioactive contamination sources-the seepage pits and trenches-in WAG 7. 


\section{EXPERIMENTAL DESIGN AND PROCEDURES}

\subsection{PIT 1 CHARACTERIZATION}

The initial step of this treatability study will be to gather the required site characterization data about pit 1 so that its ISV can be effectively and safely planned. This characterization phase is critical not only for the ISV of pit 1 but, more importantly, as a demonstration of what information is needed for ISV planning and how it can be gathered efficiently for the remedial investigation of all ORNL seepage pits and trenches. The characterization techniques and information should also support alternative remediation techniques in WAG 7, and the characterization approach should provide a useful method for other site characterization activities. Basically, the three-dimensional distribution of radioactive contamination in the pit 1 environs will be determined so that depth and lateral targets for ISV can be set. Additionally, a variety of other parameters that will affect vitrification operations will be determined, including bulk density, chemical composition, presence and amounts of groundwater, and ambient contaminant leach properties. The required characterization information and the proposed method of obtaining it is described in the following sections.

\subsubsection{Depth of Pit 1}

The actual depth of excavation of pit 1 is unknown but is presumed to be approximately $15 \mathrm{ft}$, which would be similar to the other pits and trenches; however, given the width and length dimensions of pit 1 and its stated liquid holding capacity of 200,000 gal, it is possible that the pit may be less than $10 \mathrm{ft}$ deep. Obviously, the depth of pit 1 is a critical characteristic needed to set a target depth for this ISV treatability study. The depth of pit 1 will be determined by measuring the average depth of increased resistance to penetration of a driven rod (half-inch diameter). Backfill within pit 1 will have lower bulk density than the surrounding and underlying host soil formation and, hence, should offer considerably less resistance to penetration than the undisturbed peripheral soil. Such penetration tests will be performed at 10-ft intervals on a linear transect on the long axis of the trench. Previous penetration testing techniques used for buried waste trenches and surrounding soil at ORNL SWSA 6 (Spalding et al. 1989) employed a retractable and reusable drill rod (1.25 in. diam). However, because of the higher activities of radionuclides likely to exist in pit 1 , the rod will not be withdrawn and will have only a 0.5 -in. diameter to minimize the cost of expendibles and metal addition to the pit. The smaller diameter should facilitate driving the rod with hand tools or electric vibratory hammer and should improve safety and speed field operations compared with conventional drill rig operations. The presence of residual steel rods within pit 1 will not affect ISV operations, because molten metals pool at the bottom of the melt.

\subsubsection{Lateral Extent of Pit 1}

Although the recorded dimensions of pit $1(30 \times 115 \mathrm{ft})$ are consistent with both the paving and grading plot plan dimensions (Fig. 2) and the photograph of pit 1 during its operations (Fig. 3), the exact field locations will be confirmed by penetration testing with 0.5-in. rods at $1 \mathrm{ft}$ intervals on each of two transects perpendicular to each side of pit 1 . A total of approximately 20 such penetration tests will be required; however, these tests only need to penetrate to a depth of about $5 \mathrm{ft}$ and, thus, may not encounter significantly 
contaminated material. Decisions about withdrawal of any or all penetration test rods prior to ISV operations will be made after the completion of in situ radioactivity logs, which will allow estimates of their degree of contamination to be made, as well as plans for their handling and disposal. Even if the rods cannot be withdrawn, the presence of the additional steel will not affect ISV operations; such materials have already been determined not to affect the volatility of ${ }^{137} \mathrm{Cs}$.

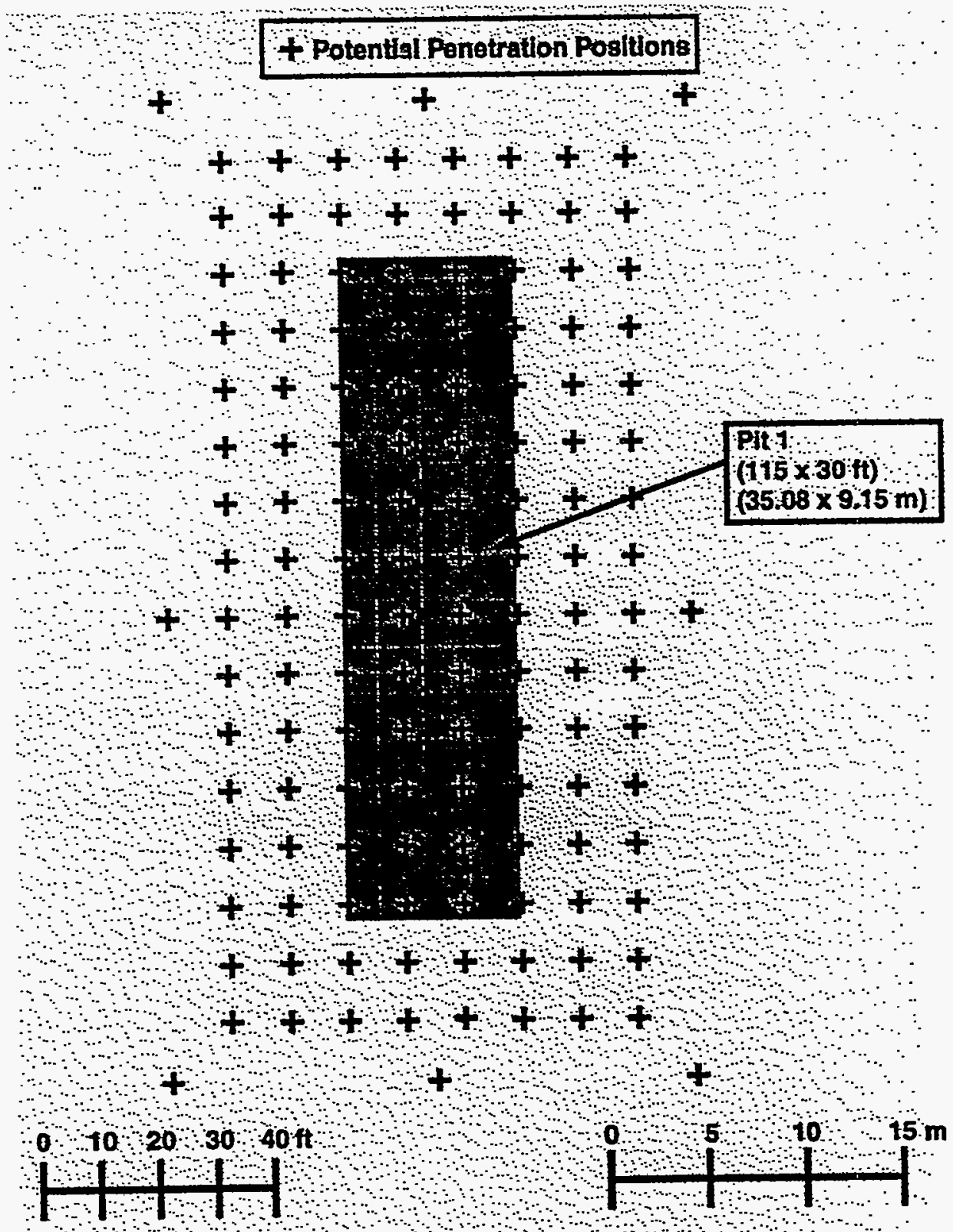

Fig. 8. Penetration point grid in and around ORNL seepage pit 1 showing maximum number of locations. 


\subsubsection{Distribution of Radioactivity Within Pit 1}

Anecdotal information from personnel present during the filling and paving of pit 1 in 1981 indicates that the pit was filled by pushing imported soil from the north to the south (Fig. 2). This activity apparently resulted in pushing sludge and liquid in the pit to the south end. Thus, it is possible that most of the pit 1 radioactive inventory is concentrated in the south end of the trench, which, if confirmed during site characterization, would present the best target for limited ISV operations. Thus, the lateral or plot plan distribution of radioactivity within pit 1 needs to be determined. To accomplish this spatial distribution characterization without producing significant amounts of radioactive sample material, in situ beta/gamma logging will be employed. Capped pipes (1.25 in. inside diameter) will be driven into pit 1 to at least $2 \mathrm{ft}$ below the pit bottom (Sect. 4.1.1) at locations to be determined interactively, based on initial results using widely spaced locations (i.e., $30 \mathrm{ft}$ apart) on two perpendicular transects through the pit. Each driven pipe will be logged in situ with both a Geiger-Mueller detector for gross beta/gamma activity and a sodium-iodide scintillation crystal detector for specific gamma emitters (i.e., ${ }^{137} \mathrm{Cs}$ ). The in situ detectors will be calibrated with the steel piping materials in soil of known ${ }^{137} \mathrm{Cs}$ activity, so that estimates of the logged inventory can be calculated. Later, a soil core will be taken proximate to at least one of the lower activity holes, so that more precise calibrations can be made with laboratory-determined activities of various depth samples. Using a grid of driven-pipe log points (Fig. 8), a planar distribution of radioactivity within pit 1 will be constructed.

\subsubsection{Vertical Distribution of Radioactivity Within and Around Pit 1}

Given the method of backfilling pit 1 prior to its paving, it seems likely that radioactivity within the pit may be concentrated near its bottom. Thus, each of the driven capped pipes (described in Sect 4.1.3) will be logged in situ at discrete depth intervals to determine a vertical distribution of activity. Considerable shielding beneath the detector may be required as it is lowered into the pipe to collimate radiation that originates lower in the pit. Additional pipes will be driven into the surrounding soil formation forming a circumference of points for assay of radioactivity distribution outside the trench. As indicated in Fig. 8, these perimeter logs will be determined at a distance of $10 \mathrm{ft}$ from the pit at a regular interval. However, the feasibility of penetrating the soil formation with driven pipe has yet to be determined. In this manner, the three-dimensional distribution of the radioactive contaminants of pit 1 will be determined without any intrusive sampling or exposure of field personnel to significant doses.

\subsubsection{Water Table Elevation Within and Around Pit 1}

At present, the elevation of the permanent water table within or around pit 1 or even the presence of perched water within pit 1 during wet seasons has not been determined. Although the presence of a true or perched water table within pit 1 will not affect the feasibility of its vitrification, it may affect the rate and, hence, the cost of its vitrification. Any moisture in the targeted region of pit 1 would be boiled away during ISV. If perched water were present and the pit's backfill were quite permeable, then the entire pit may be dried during its ISV. In addition, large amounts of boiling water beneath the ISV melt may lead to excessive bubbling of steam in the melt during operations. Although this scenario seems unlikely, given the expected high permeability of the pit backfill, such high permeability needs to be established prior to ISV operations as part of run planning. 
To determine the presence of free water in and around pit 1 , well points will be driven into at least four locations within the pit and at least four locations in the immediately surrounding soil formation to determine if pit 1 groundwater is perched or contiguous with the area's water table. Flush-joint well screen ( 24 in. long $\times 1.25$ in. diam) will be attached to solid riser pipe and driven to refusal or a maximum depth of $20 \mathrm{ft}$. Because $20 \mathrm{ft}$ is at least $5 \mathrm{ft}$ below the maximum pit 1 depth, groundwater below that elevation would not be likely to affect the ISV process at the pit bottom. Any observed groundwater will be monitored at least weekly for elevation fluctuation during the year before the start of ISV. Monitoring will also be performed at hourly intervals during several significant storm events to determine the time lag of any hydrologic connections to the surface. Any groundwater will be sampled and analyzed for radionuclides, elements determined routinely during inductively coupled plasma atomic emission spectroscopy, inorganic anions, and volatile and semivolatile organics. Such groundwater analyses will be performed initially to determine any possible hazards to site workers and, thus, determine risks during routine water table elevation measurements. Slug tests will be performed on any well point with observable standing water to determine hydraulic conductivity of the soil formation and the pit backfill. Such conductivities will enable predictions of drying rates during ISV to be calculated.

\subsubsection{Bulk Density and Porosity of Pit 1 Fill (Soil) Material}

The bulk density and porosity of pit 1 backfill and surrounding soil needs to be determined to assess the permeability of the pit material to heated gases generated during ISV and to calculate the degree of subsidence expected when melting the material. After completing the in situ radioactivity logging of pit 1 , regions of low activity, but with similar penetration resistance to the regions of high activity, will be sampled to retrieve undisturbed soil cores over the entire depth interval. One-inch diameter core tube (e.g., Geoprobe Systems Inc.) will be used. The recovered soil core will be sealed in the field sampling tubes and returned to the laboratory for determination of weight and moisture content; from the sample dry weight and core dimensions, bulk density of pit backfill and surrounding soil formation will be calculated. At least three core profiles will be collected within the pit and two from outside the pit (one upslope and one downslope). These samples will also be used for elemental analyses of the pit backfill, which will determine the melting range and other properties of the molten ISV material (see Sect. 4.1.7).

\subsubsection{Chemical Analyses of Pit 1 Soil and Fil}

The samples of pit 1 backfill and surrounding soil, obtained for bulk density determination (see Sect. 4.1.6), will be analyzed for elemental composition. The bulk elemental composition determines the temperature of melting and other melt parameters, such as electrical resistance and viscosity, during ISV. Of critical interest is the amount, if any, of limestone or dolomite present. Such alkaline earth-containing materials could well have been placed in pit 1 during operation or backfilling; such materials may also be present in the surrounding weathered strata of the Conasauga Group from which the soil material formed. These calcium- and/or magnesium-rich materials form lower-melting-temperature products when mixed with the more highly siliceous soil material. Also important is the trace element (i.e., rare earth elements) composition of the pit 1 material, because trace elements of low background concentrations will need to be selected for addition to the ISV melts for subsequent determination of the mass of ISV product (see Sect. 4.2.3). For the soil and limestone used in the 1991 radioactive test, elements such as $\mathrm{Eu}, \mathrm{Hf}, \mathrm{Lu}, \mathrm{Sm}, \mathrm{Tb}, \mathrm{Ta}$, and $\mathrm{Yb}$ 
were found at $<10 \mathrm{mg} / \mathrm{kg}$ and, thus, represent potential candidates for use as tracers. Pit 1 backfill and surrounding soil will also need to be analyzed for chloride and bromide content to determine if concentrations of these elements are different from background. As discussed previously, chloride presence during ISV can induce significant increases in the volatility of ${ }^{137} \mathrm{Cs}$; if significant levels of chloride are found (due to either residuals from the waste sludge or from discharges to pit 1 from the decontamination facility drainage), then plans for handling the volatilization of ${ }^{137} \mathrm{Cs}$ must be developed or identification of chloride-mitigating additives assessed.

\subsubsection{Radiochemical Analyses of Pit 1 Soil and Fill}

The samples of pit 1 soil and backfill, obtained for bulk density and chemical analyses (Sects. 4.1.6 and 4.1.7) will be assayed for radionuclides as described in the previous radioactive pilot-scale test (Spalding et al. 1992). Approximately ten samples, selected from the five cores in Sect. 4.1.6, will be analyzed for the complete suite of radionuclides to determine if the ratio of radionuclides is constant throughout pit 1 . If, as suspected, constant ratios of radionuclides are found, then pit 1 inventories and distributions can be calculated more accurately using the more abundant measurements of in situ and nondestructive analyses of gamma emitters such as ${ }^{137} \mathrm{Cs}$. If the ratio of radionuclides is not constant in all samples from within the pit, then independent estimates of all the nongamma-emitting radioisotopes will be attempted based on averaged or spatially interpolated activities among the actually analyzed samples.

\subsubsection{Melt Properties of Pit 1 Soil and Fill}

Using the elemental analyses of pit 1 soil and backfill (Sect. 4.1.7) and the models of Shade and Piepel (1990), analysts will calculate the melting properties and electrical resistance of molten material. They will also use the MELTS code of Ghiorso (1987) to model the potential crystallization behavior of the expected melt composition. Methods similar to those developed in previous studies (Spalding et al. 1989) will be used when samples are subjected to melting in laboratory crucibles to verify the predicted melting ranges. In addition, the effects of ambient co-contaminants (e.g., chloride) on the volatilization of ${ }^{137} \mathrm{Cs}$ from samples of pit 1 soil and backfill will be assessed in such laboratory melts. Comparative melting experiments with limestone amendments and their associated lower ISV operating temperatures will be performed to determine if volatilization of ${ }^{137} \mathrm{Cs}$ can be reduced from what was experienced when unamended pit 1 soil was tested.

\subsubsection{Sludge Chemical and Radiochemical Composition}

From the results of the in situ radioactivity assays, the zone of highest activity will be selected for sampling. Researchers will use a driven probe (e.g., Geoprobe Systems, Inc., soil sampler) to sample the selected depth interval to produce approximately $2 \mathrm{ft}$ of 1 -in. diameter undisturbed "core." The core will be withdrawn by hand into multilayered plastic sleeves (tubing) and placed into a shielded container, if required by the radiation field intensity. Field observations and photographs will be employed to determine if this zone of highest activity is a physically distinct "sludge" or merely a highly contaminated soil or backfill. Regardless, it will be designated as the "sourcen material contaminating the pit 1 environs. ORNL hot cell analytical services will assay the sludge for elements and radionuclides as described previously for the pit 2 sludge used in the 1991 radioactive test (Spalding et al. 1992). Particular 
chemical characteristics, such as the chloride and borate concentrations that are known for their potential to increase the volatility of ${ }^{137} \mathrm{Cs}$, will be measured. Samples of sludge will be melted in laboratory crucibles with pit 1 soil and/or backfill to determine potential volatility of the ${ }^{137} \mathrm{Cs}$.

\subsubsection{Sludge Leach Properties}

The "sludge" or source contaminated material from pit 1 , collected by the methods described in Sect. 4.1.10, will be subjected to sequential leaching with dilute calcium chloride and dilute hydrochloric acid to simulate its weathering behavior (Spalding et al. 1992). As previously, it will also be subjected to toxicity characteristic leach procedure (TCLP) and product consistency test (PCT) leaching procedures (Janzten and Bibler 1989), so that its waste form performance can be compared with other materials and with the final ISV product made from it. A scaled-down version of ASTM Designation D 5233-92, Standard Test Method for Single Batch Extraction Method for Wastes, will be performed on contaminated source material from pit 1.

\subsubsection{Site Preparation for ISV}

The spatial distribution of radioactivity will determine the selection of many options for performing ISV operations and configuring melt geometries. In order to initiate ISV melts, a portion of the present asphalt cap on pit 1 will need to be removed; the nominal 2-in.-thick cap will be sampled to ensure that it is not radioactively contaminated and then removed for disposal. The area surrounding the pit, which is presently covered by grass and maintained by mowing, will need to be covered with gravel to provide all-weather access for ISV equipment and vehicles. Portions of the area will be zoned off during certain site characterization activities, such as sludge sampling, and during ISV operations. The results of the in situ activity assays will be used to determine the depth of uncontaminated surface soil and, possibly, of fill materials that might be graded or moved to level any area needed for ISV operations. The penetration resistance of surrounding soil and, more importantly, the pit 1 cover and backfill will determine load bearing capacities of these materials for ISV equipment, particularly the off-gas hood. Locations for main and auxiliary generators, their associated fuel tanks, and backup electrical service through existing power lines will need to be planned for site operations, taking into consideration the known surface contamination (Carrier et al. 1989) and the to-be-determined shallow subsurface contamination at the site.

\section{ISV MELTING OPERATIONS}

The second phase of this treatability study will be the field melting operations at pit 1 employing at least two settings to achieve overlapping and fused melts. Such field operations are likely to require 6 to 8 weeks (including mobilization and demobilization of ISV equipment) to complete and should proceed smoothly, based on the successful completion of site characterization. The ISV melting operations will follow established PNL Safe Operating Procedures (SOPs) and the test plan for operation of either the pilot-scale or large-scale equipment. However, considerable development or modification of ISV off-gas handling equipment will need to be performed to meet the objectives of this pit 1 treatability study. 


\subsubsection{Depth and Lateral Goals}

The pit 1 characterization should provide adequate data from which to establish the three dimensional distribution of radioactivity within pit 1 . This information will be used to set depth and lateral goals for the two or more melt settings of pit 1 ISV operations. Because there are not presently sufficient resources to vitrify the entire pit 1 contaminated volume in this treatability study, priorities for selecting portions of pit 1 for vitrification will be, in order, (1) depth, (2) lateral completeness across the entire pit width, and (3) maximum incorporation of radioactive contamination into the ISV product. Although the depth of contamination at ORNL pit 1 may be as shallow as $10 \mathrm{ft}$, a depth goal of $15 \mathrm{ft}$ will be adhered to, because ISV will be required to attain this depth at other ORNL seepage pits, such as pits 5, 6, and 7, which are known through construction photographs to be at least $15 \mathrm{ft}$ deep. If the penetration testing of pit 1 exhibits hard layers at significantly less depth than $15 \mathrm{ft}$, then the depth goal may need to be reduced; such hard layers would indicate residual limestone strata through which ISV may proceed quite slowly compared with lateral and less dense material within the pit. Thus, a $15 \mathrm{ft}$ depth may not be reasonably attainable if such hard layers underlie pit 1 . Secondary to the depth goal would be a lateral goal of achieving melted material from side to side in one region of pit 1 by using multiple settings to overlap melts. Ideally, this could be attained in one setting of a large-scale unit or two settings of the upgraded (1.25-MW) pilot-scale unit. Determination of the behavior of the ISV melt on contact with the undisturbed soil boundary will be a critical goal of this treatability study; such behavior will determine operating scenarios and necessary electrode configurations for ISV of all the seepage pits and trenches. The third priority in setting pit 1 depth and lateral goals will be to incorporate the maximum amount of the radioactive inventory within the final ISV zone. If the "sludge" within pit 1 was plowed to the south end of the pit during its filling operation [as found by Lomenick et al. (1967) in characterizing ORNL pits 2 and 3], then simply selecting the south end of pit 1 may maximize the inclusion of radioactive contamination within the ISV product.

\section{Selection of Melt Additives}

Based on elemental analyses and the behavior of the pit 1 soil and backfill in laboratory melts, potential melt additives for the field ISV will be considered. Two potential contingencies would necessitate the consideration of melt additions: (1) to reduce ISV operating temperatures by addition of limestone either if more rapid ISV production could be attained or if lower operating temperatures would aid in minimizing volatilization of ${ }^{137} \mathrm{Cs}$ or (2) to reduce volatilization of ${ }^{137} \mathrm{Cs}$, induced by the presence of chloride in pit 1 . Zinc, cesium, and potassium carbonates and oxides have recently been found to perform this function during laboratory crucible melts. Specific methods for adding such materials during or before ISV will need to be developed. For example, to adjust the calcium composition of the melt, significant amounts of limestone (e.g., 20 to 30 tons) would need to be added. This could be accomplished through a solids-delivery hopper on the off-gas hood or through preplacement within the melt area in shallow excavations before initiation of ISV.

\section{Selection of Melt Tracers}

Based on the trace element analyses of pit 1 soil and backfill (Sect. 4.1.7), tracer elements will be selected for addition to each of at least two of the two or more melt settings. By adding known amounts of at least two tracers to each setting, their final concentrations 
in the ISV product can be used to calculate the mass of ISV product. Tracer elements would be emplaced at depth within the central region of each setting with access via a driven pipe; the access pipe will be withdrawn prior to initiation of melting. Experience in the 1987 and 1991 field ISV test melts has shown that all elements and radionuclides are quite uniformly distributed within the ISV product due to the convective flows and resultant mixing within the molten material during processing. Two tracers will be used in each melt setting so that this critical calculation of product mass will not depend on a single element determination. The calculated melt masses will also be used to determine the inventory of each radionuclide incorporated into the product of each ISV setting, based on the measured activities in each product. Such inventories will be essential to calculating melt retention factors and mass balances for elements and radionuclides, particularly the semivolatile ${ }^{137} \mathrm{Cs}$. Without tracer element additions and product analyses, melt masses could only be estimated roughly from measured melt depths, product densities, and subsidence volumes.

\section{Off-Gas Hood Design and Fabrication}

Because of the unique size of ORNL pit 1 and the likelihood of significant off-gas contamination, the off-gas hood for this treatability study must be designed for site-dedicated use. If possible, the off-gas hood will be designed so that it meets the future ISV operating needs of all the ORNL seepage pits and trenches. In particular, the off-gas hood components that contact contaminated off-gas and, thus, would likely become contaminated will be designed to accommodate either (1) decontamination methods or contamination fixation methods during hood mobilization, both between multiple settings at one site and between operations at different sites, or (2) replacement of components if contamination exceeds radiologically safe levels. Use of ceramic or glass fabric liners for the actual stainless steel hood surfaces will be considered; such fabrics could be lowered into the subsidence zone at the conclusion of each melt setting. The off-gas hood design will also address the need to incorporate a prefiltration system for removal of ${ }^{137} \mathrm{Cs}$, preferably within the off-gas hood. Hood size and geometry design will consider aerodynamics of off-gas within the hood, off-gas pressure surge damping capacity, and ground surface distances and slopes to be spanned for assured structural support during ISV operations.

In addition, the off-gas hood designers will consider incorporating a capability to handle and replace broken graphite electrodes; the presence of large graphite fragments on or in the ISV melt can cause significant electrical arcing, which could ultimately require termination of operations. A remotely (i.e., outside hood) operated gripper or manipulator may provide this capability and could be designed into the off-gas hood. The electrode grippers for the present pilot-scale off-gas hood will be redesigned to avoid deterioration problems during melting operations and the electrode feeders will be redesigned to accommodate electrodes of variable size (i.e., 6 through 12 in.). Sealing of the off-gas hood to the ground surface will also be reconsidered to avoid decreases in operating hood vacuum as surface soil dries out; this might be accomplished through multispeed off-gas blowers or through a moistening system around the hood base.

\subsubsection{Off-Gas Hood Filtration System}

In the 1991 radioactive test (Spalding et al. 1992), prefiltration of the off-gas with glass HEPA filters was found to remove ${ }^{137} \mathrm{Cs}$ effectively before off-gas was cooled, scrubbed, and filtered in the ISV processing trailer. The prefiltration technique will be used in this 
treatability study with the design goal of achieving such off-gas prefiltration within the off-gas hood. Conceptually, HEPA filter materials could then be returned to the melt in its later stages when volatilization rates of ${ }^{137} \mathrm{Cs}$ had subsided. Renewable prefiltration material (i.e., a roll of material) will be considered to avoid solids build up on the filter surface and associated pressure drops or impeded off-gas flow. Alternative filtration materials and combinations of materials will be considered for the prefiltration design. In addition, a recent finding that floating alumina beads function as an effective thermal barrier on ISV melts holds promise for seepage pit application; such a thermal barrier would also be expected to function as an in situ filter for condensing or trapping volatilized ${ }^{137} \mathrm{Cs}$. Such a floating thermal barrier capability will be incorporated into at least one of the melt settings at the pit 1 ISV operations.

\subsection{Off-Gas Monitoring}

Off-gas from the ISV melts will need to be continuously monitored for radioactivity, which will be composed almost exclusively of ${ }^{137} \mathrm{Cs}$ (Spalding et al. 1992). In the 1991 radioactive test, real time radioactivity monitoring was achieved through beta/gamma (GeigerMueller) assay on one of the MM5 standard sampler filters. Although this worked well for determining when the ISV melt first encountered and volatilized some ${ }^{137} \mathrm{Cs}$, the buildup or integration of activity on the filter did not allow detection of fluctuations in evolved activity and, thus, sensitive real time resolution. For the present treatability study, a continuous data logging monitor will be employed. A monitor similar to the Westinghouse Series 1300 Air Particle Detector-Moving Filter will be employed; in this device off-gas is pulled through a rolling sheet of filter paper at discrete intervals, which are then assayed and logged by means of a scintillation detector. At least two of these monitors will be used to monitor the off-gas and will provide both a data and sample record of radioactive emissions from the melt. One monitor will sample off-gas directly from the off-gas hood, with the second monitor positioned to sample from the off-gas line downflow from the prefiltration system.

In addition to the routine pressure and temperature monitoring of the ISV off-gas, stack sampling will be employed continuously in the off-gas line and at the processing trailer stack for air emissions of radionuclides in compliance with 40 CFR 61, subpart $H$, National Emission Standards for Emissions of Radionuclides Other Than Radon From Department of Energy Facilities. Evacuated canisters, described in previous tests (Spalding et al. 1992), will be used to sample fixed gases at intervals during the runs. To determine the amount of water originating from the ISV melt, off-gas monitoring techniques will also be developed for off-gas moisture content, and a method will be derived for calculating contributions from inleakage to the off-gas hood by ambient atmospheric humidity. Depending on the concentrations of nitrate, sulfate, and tritium found within the target regions of pit 1 during site characterization, emission monitoring capabilities for these volatile species (i.e., $\mathrm{NO}_{x} \mathrm{SO}_{x}$ and ${ }^{3} \mathrm{H}$ ) may be needed in the off-gas processing trailer stack.

\section{Electrode Spacing Selection}

The selection of electrode spacing is critical to selection of the ISV unit (pilot- or largescale) and melt geometry desired. The minimum default scenario, as discussed in Sect. 4.2.1, would be electrode spacing of $8 \mathrm{ft}$. This spacing would yield a melt volume with a maximum diameter of $16 \mathrm{ft}$ and would yield side-to-side overlapping melts in one transect of pit 1 . Whether these side-to-side overlapping melts can be attained using the upgraded (1.25 MW) 
pilot-scale unit in two or three settings will be determined after operational testing of the new pilot-scale unit. The entire backfilled volume of pit 1 to an assumed depth of $15 \mathrm{ft}$ would be about $50,000 \mathrm{ft}^{3}$, while the volume to an assumed $10 \mathrm{ft}$ depth would be about $33,000 \mathrm{ft}^{3}$. The weights of soil to be vitrified would be 1567 and 1044 tons, respectively, assuming pit backfill has an average bulk density of $1.6 \mathrm{~g} / \mathrm{cm}^{3}$. If a single $16 \mathrm{ft}$ wide segment were produced across one end of the 115-ft-long pit (i.e., 14\% of its total volume), then ISV would need to produce between 131 and 197 tons of melted material, assuming $90 \%$ weight retention after melting from an oven-dry condition. Electrode spacing will be optimized to ensure attaining the $15 \mathrm{ft}$ depth goal if geologic features allow; otherwise, electrode spacing will be selected to attain the target depth with the minimum number of settings necessary to attain side-to-side overlapping melts.

\subsection{Melt Depth and Width Monitoring}

To verify when and if melt depth and width goals have been attained during field operations, monitoring of melt progress will be performed. Three basic methods will be employed: (1) electrode depth penetration, (2) thermocouple data at selected discrete depth intervals, and (3) a non-electrode graphite or ceramic shaft employed as a dipstick In the 1991 radioactive test (Spalding et al. 1992), the depth of penetration of each of the four graphite electrodes during the test provided accurate estimates of melt depth compared with the data from the burnout of type-K thermocouples in a central bundle within the melt. Thus, electrode penetration depths will continue to be the primary depth monitoring technique for this treatability study. The electrodes are, however, subject to breakage and oxidative corrosion during ISV, and, although electrode segment replacement is relatively facile, allowing continued ISV operation without significant interruption, such replacement can introduce uncertainty in the estimate of remaining electrode length and subsequent depth measurements. The 1991 test employed a trench that was specifically constructed to allow the placement of thermocouples at most desired locations; the thermocouple must penetrate to the desired location with the lead wires directed away from the zone to be melted. This restriction greatly minimizes the use of thermocouples in the pit 1 ISV treatability study, because the regions to be monitored cannot be excavated for thermocouple placement. Thus, ISV depth and width monitoring via thermocouples at pit 1 will be attempted using thermocouples driven at oblique angles to horizontal or near horizontal from the steep slope to the west of the pit (Fig. 2). Although many of the type-K thermocouples must be assumed to cease functioning prior to melt arrival at their tip if lateral melt intrusion intercepts their angled leads, the relative low cost of type-K thermocouples will allow placement of many redundant thermocouples at crucial depth locations. The third method of depth monitoring will use a specifically designed retractable graphite or ceramic dipstick attached to the off-gas hood. At selected run durations, the dip stick will be lowered, using a specially designed feed mechanism, to the bottom of the melt. Just before turning off power, this device will also be used to sample the final ISV product through a hollow stem capillary within it.

\section{Melt Temperature Monitoring}

As discussed above (Sect. 4.2.8), thermocouple monitoring will be used to ascertain ISV melt depth. In addition, actual operating temperatures and cooling will be monitored with alumina-sheathed type- $C$ thermocouples; these sheathed thermocouples worked extremely well for both operational and postoperational thermal monitoring during the 1991 ORNL test (Spalding et al. 1992). Again, these will need to be positioned within the projected melt 
volume through oblique-angle insertion. The measured operating temperatures will be compared with the predicted operating temperatures for the probable elemental composition of the melt (Shade and Piepel 1990). Additional alumina-sheathed type-C thermocouples may be inserted into the melt from the top during or at completion of operations. All thermal monitoring and process monitoring will be collected in a personal computer controlled data acquisition system, similar to that employed in the 1991 ORNL radioactive test.

\subsection{Generator Selection}

Because other ORNL line electrical system user needs on the same feeder line through ORNL WAG 7 were compromised during both the 1987 and 1991 ISV tests, future power for the ISV melts cannot be supplied from the ORNL line system. Thus, electrical power for the ISV electrodes will be supplied using a portable, rented generator for this treatability study at pit 1 . The output capacity of the generator will be selected to match the 1.25-MW pilot-scale or the 4-MW large-scale unit, which will have been selected to meet the depth and lateral goals of the treatability study. The electrical power for process control, off-gas processing, and data monitoring will be supplied by the ORNL line feeder system. A backup generator will also be installed at the pit 1 site to operate these same control and monitoring systems (approximately $150 \mathrm{kVA}$ required) in the event of an interruption in line power.

\subsection{Off-Gas Hood Demobilization and Storage}

Following completion of the last field melt setting at pit 1, the off-gas hood will need to be stored until it is needed for future stabilization and closure of ORNL seepage pits and trenches in WAG 7 or for other buried waste or underground storage tanks at ORNL. The design of the off-gas hood will minimize its potential for contamination during ISV operations and/or facilitate its decontamination (Sect. 4.2.4); however, some level of residual radioactive contamination will likely remain on some components of the off-gas hood. For the dual function of determining the degree of off-gas hood contamination and computing the mass balance and distribution of semivolatile radionuclides (i.e., ${ }^{137} \mathrm{Cs}$ ) and elements, all internal surfaces of the off-gas hood and piping will be surveyed and sampled by smearing. Procedures for this process will be similar to those employed in the 1991 radioactive field ISV test. Alternatively, removable metallic coupons could be positioned within the off-gas hood and pipes to allow sampling from outside, thereby obviating the need for personnel access into potentially contaminated equipment. Following completion of the contamination survey and any decontamination efforts, the entire hood will be stored inside a specially fabricated UVstabilized polyethylene membrane cover on the undisturbed portion of the asphalt pad covering pit 1. As in the 1991 test, affected off-gas components were found to be contaminated only with radioactivity; thus, existing waste disposal operations at ORNL should be able to accept these contaminated components for on-site disposal.

\subsection{Melt Visual Monitoring}

Continuous video monitoring and recording of the behavior of the melt surface and inside off-gas hood conditions will be performed. Much of the melt bubbling activity, incandescence, and electrode corrosion can be assessed and reviewed, if necessary, by this method. A similar monitoring effort was made during the 1991 radioactive field test; however, a buildup of aerosol particulate on the window surface, due to failure of the pneumatic clearing device, obscured the camera view after about a day of operations. Thus, the 
window(s) for video viewing at pit 1 will be fitted with a high-temperature wiper to overcome this problem. The brightness of molten material during early stage of the melt often saturated the optical system in 1991; therefore, provision for inclusion of optical filters and aperture control to overcome this problem will be provided for pit 1 operations. In addition, a second continuous video recording of a comprehensive site view will be produced to document any unusual occurrences outside the off-gas hood during ISV operations.

\subsection{POSTTEST PRODUCT AND SITE CHARACTERIZATION}

Following termination of ISV melting operations at pit 1 and demobilization of ISV equipment and the off-gas hood, posttest characterization activities will begin. Such characterization will focus on process performance and product quality. An evaluation will be performed to determine the level of success in meeting all project objectives. A variety of characteristics will be assessed in this evaluation.

\subsubsection{Product Sampling}

After cessation of power to the melt settings and after thermal monitoring indicates that the field product has returned to near ambient temperatures (an interval of two to six months may be required, depending on the mass of product), the ISV product will be sampled for chemical and radionuclide characterization and leach testing. In 1991 posttest sampling, diamond-tipped rock coring was found to provide good core recovery and sample quality (Spalding et al. 1992). Two complete cores will be obtained from each of the melt settings from the region within the electrode array. An additional core will be obtained from a region of melt setting overlap. The breakthrough depth (i.e., the depth at which the core barrel drops into comparatively soft unmelted soil) provides critical data for verifying melt depth (see Sect. 4.2.8). Field descriptions of the core are also essential in establishing needs for additional coring. Field monitoring of product core radioactivity will also determine whether the samples need to be processed in shielded hot cells, glove boxes, or can be processed in laboratory hoods. Because field product will be sampled with the graphite rod dipstick at the end of each melt, a good estimation of expected product activity and, thus, its handling procedures will be known prior to coring. In addition, prior to placing clean soil backfill into the resulting subsidence craters, selected cold cap or ledge material will be retrieved with mechanical extension grippers. Selected sections of core material will be pulverized with a ball mill, as described in the previous study (Spalding et al. 1992). Residual core will be archived for use in future studies. The resulting boreholes through the ISV product will provide access to drive well points beneath the vitrified zone for groundwater elevation and quality monitoring (see Sect. 4.3.4). These cased wells will also be monitored at intervals, by means of the in situ radiation detectors described for pit characterization (Sect. 4.1.3), to determine any changes during the posttest monitoring interval. Prior to driving well point screens into the ISV product sampling coreholes, each corehole will be logged with a borehole caliper probe to determine the presence, absence, size, and orientation of any fractures or voids. In addition, a borehole video camera will be used to log the depth, orientation, and morphology of any fractures or cavities in the ISV melt zone. In situ beta- and gamma-activity logs will also be performed similarly to the pre-test characterization techniques (sections 4.1 .3 and 4.1.4). 


\subsubsection{Product Chemical and Radiochemical Analyses}

The various samples from the ISV cores will be used for chemical and radionuclide characterization of the product. Major and trace elements will be analyzed by X-ray fluorescence and neutron activation analyses, as described previously (Spalding et al. 1992). Of particular importance will be the four rare-earth tracers (i.e., two in each of at least two melt settings); the concentrations of these will be used to calculate ISV product mass based on the known additions to each setting and ambient background concentrations in the pit soil and backfill. Radionuclide analyses of these same samples will be performed as in the previous test; from the measured activities of each radionuclide and the independently calculated product mass obtained from measured tracer concentrations in the product, the inventory of each radionuclide in each melt setting product can be calculated. These inventories will be crucial for calculating melt retention factors for each radionuclide, particularly the semivolatile

${ }^{137} \mathrm{Cs}$. The degree of melt overlap will be determined from the tracer concentrations in the core samples taken from the region of suspected overlap. More likely, in samples from the second melt setting, the concentrations of tracers that were placed into the initial melt setting will provide a method to calculate the volume of the first melt, which was incorporated into the second melt.

\subsection{ISV Product Leaching Characteristics}

Samples of the pulverized ISV product that were used for chemical and radionuclide analyses will be subjected to PCT leach tests and the dilute $\mathrm{CaCl}_{2}$ and $\mathrm{HCl}$ leaching procedures that were used in the previous study (Spalding et al. 1992). These data, when coupled with those obtained from identical tests on the starting contaminated source material (see Sect. 4.1.11), will allow a direct comparison of before-and-after leachability of the pit 1 radionuclide contamination. If elements of concern in the TCLP are found in sufficient concentration in the ISV product, then TCLP tests on pulverized and whole (core fragments) ISV product will also be performed. An actual or scaled-down version of ASTM Designation D 5233-92, Standard Test Method for Single Batch Extraction Method for Wastes, will be performed on ISV product from pit 1 . Sections of cored product will be used for this test without grinding or sieving as specified in the method. If radiation levels in the ISV product permit handling and operations in a chemical laboratory, method D 5233-92 will be performed at the specified sample size of $100 \mathrm{~g}$.

\subsubsection{In Situ ISV Product Performance}

The suspected presence of perched or true groundwater within and around pit 1 should provide a unique opportunity to evaluate ISV product performance in situ. The presence and quality of groundwater within pit 1 will be monitored for the year before vitrification of the source contamination within pit 1 . Although ISV will likely result in drying the pit during its heating, even in adjacent unvitrified regions, standing water will return around the ISV product after cooling to ambient conditions. Thus, actual water quality within and under the ISV product can be determined through analyses of posttest water samples. Access to water within and under the ISV product can be gained through the resulting boreholes from product sampling (see Sect. 4.3.1). After some initial period of flushing and percolation, sampling of such groundwater in contact with the ISV product should provide excellent in situ weathering and release kinetics for predicting the long term performance of the actual fieldscale ISV waste form. Obviously, unmelted regions of the pit may influence apparent 
groundwater quality within and under the ISV product depending on flow patterns within the pit, and such confounding effects will need to be assessed. The posttest water table observation wells will be used for a minimum of one year after completion to determine water table fluctuations and water quality effects.

\subsubsection{Product Mineralogical Characterization}

Depending on the elemental composition of the ISV melt and its cooling kinetics, crystalline as well as vitreous product may be formed, which was experienced in the 1991 ORNL radioactive test. Using the core material collected as described in Sect. 4.3.1, degrees and extent of crystallinity can be assessed by visual and microscopic examination of the product from different regions of the core and, hence, different cooling regimes. The resulting mineral products formed will be compared with predictions based on elemental composition and cooling information concerning igneous rocks and minerals. If distinctly different minerals are formed or if a mixture of crystalline and vitreous products are formed, leaching characteristics for each gross type will be collected (see Sect. 4.3.3).

\subsubsection{Off-Gas Analyses}

In addition to the real-time monitoring of ISV off-gas, described in Sect. 4.2.6, posttest activities will include obtaining samples from several off-gas system components. First, the prefiltration material(s) will be sampled to determine the inventory of radionuclides on this primary sink for any volatilized activity. As in the 1991 radioactive test, multiple samples will be collected of these materials to measure radionuclides, elements, and total solids evolved from the melt. The absence of the tracer rare-earth elements must also be determined to establish their conservation in the melt and, thus, validate their use in calculating melt mass. Information from these samples will be supplemented by the analyses of samples collected from the internal surfaces of the off-gas hood and piping (Sect. 4.211). In addition, the offgas scrub solutions in the processing trailer will be sampled on a regular basis (e.g., after each incremental foot of melting or six hours of operations); these samples will verify that radionuclides have not permeated the prefiltration device. Real-time continuous off-gas radioactive monitoring will be determined with the scintillation detector (Sect. 4.2.6). Filters from the isokinetic off-gas flow samplers (MM5) will also be analyzed for radioisotopes and elements. If time resolution of particular elements in the off-gas should prove desirable or necessary, the continuous filter strips of the real-time radioactivity monitor (Sect. 4.2.6) will be employed for additional destructive analyses.

\subsubsection{Site Decommissioning}

Clean soil fill will be brought to the pit 1 site to fill the subsidence craters from the overlapping melts. The volume of the subsidence will be estimated by surveying elevations and measuring average widths. Numbers, orientation, depths, and morphology of any cold cap remnants or ledges will be described and photographed. The surface will be graded and compacted to match existing contours and additional asphalt will be placed to match the existing cap. However, this restored asphalt cap will not be completed until core sampling of the ISV product and posttest monitoring well installation have been completed. During intervals when the site is not being accessed, the area will be covered with a waterproof tarp. 


\section{EQUIPMENT AND MATERIALS}

A listing of all equipment and materials for this ISV treatability study would be extremely long and will not be attempted here. A list of major equipment components and their functions is given here.

1. Off-gas hood-to collect off-gas from ISV; specifically designed and fabricated for pit 1 and future ISV operations within ORNL WAG 7.

2. Off-gas prefiltration system-to remove volatile radionuclides from the ISV off-gas (either near or within the off-gas hood) and possibly return captured material to the current or subsequent melt.

3. Upgraded (1.25-MW) pilot-scale or 4.0-MW large-scale ISV unit-to perform ISV on at least two overlapping settings at ORNL pit 1 to a depth of $15 \mathrm{ft}$.

4. Generator(s)-one to provide power for ISV melting operations and a second to provide backup power for process operating components and data logging equipment.

5. Electrical power-to supply primary power to the site via the ORNL line system for operation of process equipment (not electrode power) and data logging equipment.

6. Data acquisition system-a personal computer system and software to record all thermocouple, flow, pressure, and electrical power parameters.

7. Supplemental portable site building - to house instruments and field samples during pretest and posttest characterization activities and to house the backup data acquisition system during ISV operations.

8. Personnel decontamination portable building - to house personnel protective equipment and clothing and to provide contingency decontamination facilities for personnel at the site. 


\section{SAMPLING AND ANALYSIS}

Samples will be collected and analyses performed during each of the three phases of this ISV treatability study: pretest site characterization, ISV site operations, and posttest product and site characterization and monitoring. Many different types of samples (groundwater, soil, backfill, off-gas, filters, sludge, ISV product, scrub solution, HEPA filter, and hood and piping surfaces) will be collected, and many different types of parameters will be measured. A detailed schedule planning the types, number, and frequency of sampling would be highly speculative at this stage of project initiation because of the interactive or observational approach being taken. This is particularly applicable for the pretest site characterization activities, which will provide information needed to set goals and specific objectives for ISV operations and subsequent posttest characterization activities. The objectives of sampling and analyses are defined in the description of experimental design and procedures (Sect. 4). Detailed methods and associated references have been described in the report of the 1991 radioactive field test at ORNL (Spalding et al. 1992) and are not repeated here. The remainder of this section summarizes the goals and approaches for each of the three phases of this treatability study. Sampling and analysis is a major contributor to the costs of the treatability study and types, numbers, and frequencies of sampling were assumed to be similar in aggregate cost to the effort in the 1991 radioactive test. If resources become constrained, sampling strategy can change to support the study's priority of objectives (Sect. 3).

\subsection{PRETEST SITE CHARACTERIZATION}

Significant characterization information on pit 1 must be obtained before the ISV may be implemented. The major objectives of pit 1 characterization are to determine (1) the inventory of radionuclides present in the pit, (2) the chemical composition of pit 1 backfill and surrounding soil and their compatibility with vitrification, and 3) the depth and lateral distribution of radionuclides to establish targets for ISV. The methods tested in this treatability study will be evaluated for inclusion in the RI/FS for all of WAG 7. Specifically, the characterization techniques, including source sampling, that are most useful for implementing ISV as the WAG 7 closure alternative will be established. The inventory and spatial distribution of radioactivity will be determined through the use of driven well points and subsequent in situ gamma radiation logging. An initial grid of six well points within the pit and an array of 14 well points $10 \mathrm{ft}$ from the pit 1 perimeter will be employed. These well points can be placed without augering or tool removal, which might lead to significant radiation exposures for personnel or risks of environmental releases during field operations. Likewise, depth to groundwater and/or perched water within and around the pit will be determined via these well points. Once the depth profiles of radiation have been determined, samples of backfill will be obtained from additional well points with detachable drive points. The nature and extent of any nonradioactive contamination will be determined for these source samples, as well as their melting and vitrified characteristics. The actual depth and lateral extent of the pit will be confirmed from penetration resistance during well point installation. Slug tests will be performed using both air and water to determine the permeability of the pit's earthen materials. Some of this site characterization will be completed in FY 1993 so that final positioning of test melt sites can be specified and target depths established. Determination of the inventory will allow more confident safety assessment of the radiation hazards to be determined prior to ISV operations. 


\section{ISV OPERATIONAL MONITORING}

Operational monitoring during ISV will verify that depth and width melting goals are met and will document the operational parameters (e.g., electrical power and electrode penetration) necessary to accomplish those goals. Operational monitoring will also determine real-time volatilization of semivolatile radionuclides from the melts, as well as the quantity and quality of air emissions from the ISV activities. The performance of specifically designed offgas hood and off-gas prefiltration systems will be evaluated for use in subsequent remedial actions at ORNL. Melt temperature monitoring during both melting and cooling will be performed to correlate with power inputs and off-gas emissions monitoring data. Automatic monitoring and recording of most thermal, pressure, and flow information will be performed using two data acquisition systems.

\section{POSTTEST PRODUCT AND SITE CHARACTERIZATION}

Posttest characterization centers on verification of depth and width of melt(s), based on coring of the product. This sampling activity will also provide material for chemical, radionuclide, and tracer analyses from which melt mass can be calculated and melt retention and distribution of radionuclides and elements determined. The melt retention factors will enable process performance safety and control measures to be planned for actual remediation actions in ORNL WAG 7. The core samples will also be used in leach tests for field-produced product quality assessment. Based on this information, the benefit of ISV on long term site performance can be assessed. Verifying that depth and lateral goals were obtained during ISV will aid is establishing operational approaches for ISV of all the ORNL seepage pits and trenches. Off-gas system components will also be intensively sampled after the field activities to determine the amount and distribution of any volatilized contaminants; components include the off-gas hood and piping surfaces, the prefiltration material, the off-gas scrub solutions, and the final HEPA filters in the processing trailer. The degree of surface subsidence induced by the ISV of pit 1 material will be measured and compared with the mass of product formed. The subsidence crater(s) will be filled, graded, and, ultimately, recapped with asphalt to restore the site grade and pretest asphalt cap. The cooling of the ISV product will also be monitored to determine the kineties of return to ambient temperature; delays in cooling have been found to be indicative of crystallization of ISV product (Spalding et al. 1992). 


\section{DATA MANAGEMENT}

All data and project planning and analysis will be maintained by principal investigators in registered data notebooks; a summary list of all notebooks and their contents will be maintained by the project manager. These will be updated quarterly at a minimum and more frequently during intervals when data generation is increased. Record copies of all project documentation (reports, permits, correspondence, plans) will be maintained by the project manager in office files. Reports of chemical and radiochemical analyses of environmental samples will also be maintained by the project manager. Data generated during operational performance of the ISV melts and recorded on the computerized data acquisition system will be stored on removable hard drives; backup copies will be made within $24 \mathrm{~h}$ on additional removable hard drives (e.g., Bernoulli disks) or alternative computer hardware systems. A list of all computer files and their locations will be maintained by the project manager. The operational notebook log of the ISV melts and related activities will be prepared by the operational staff of PNL with concurrent "read-and-understood" annotation by ORNL staff; copies of this operational log will be made before PNL personnel and process equipment leave the ORNL site at completion of field activities. Review comments on all reports and documentation will be maintained by the project manager. Photographs of significant site characterization activities, site preparations, ISV operations, and posttest characterization activities will be prepared with record (original prints) copies and a list of all photographs maintained by the project manager. Video recordings will also be prepared of similar significant operations. In addition, a complete and continuous video log of ISV site operations and melt surface activity will be prepared to provide documentation of any unusual occurrences. 


\section{DATA ANALYSIS AND INTERPRETATION}

The inventories of radionuclides in seepage pit 1 will be computed by interpolation and integration of in situ gamma activity logs of boreholes in and around pit 1 . This data will be presented graphically for summarization. This site characterization will be used to set targets for ISV melting depths and areas that will be compared later with the actual results of ISV operations. Segments of pit 1 to vitrify will be selected for maximum incorporation of radioactivity within the melted volumes.

ISV operational parameters will be summarized graphically as in previous reports (Spalding et al., 1992). Melt depth and volume versus time of operation will also be presented graphically from the elevation measurements of the graphite electrodes and the burnout of type-K thermocouples prepositioned in the melts. Although electrical energy consumption will be used as a crude estimate of ISV product (i.e., using a constant $\mathrm{kg}$ of vitrified product/kwh of electric power based on previous ISV experience), the final ISV mass will be determined independently. Melt mass will be calculated from the concentrations of added tracers in cored samples of the ISV products and the known amounts of addition to each melt. The calculated melt masses, when coupled with the concurrent determinations of activities of the various radioisotopes and their ratios to each other, will enable the inventory of each radionuclide in each melt to be calculated. Thus, a mass balance for each radioisotope and element can be produced and, from the analyses of off-gas filter materials, estimates for the retention of each element and radioisotope can be computed.

ISV product leaching quality will be tested via both PCT methods and calcium chloride/dilute hydrochloric acid leaching as performed previously (Spalding et al. 1992). A direct graphical comparison of the ambient pit 1 sludge in these same leach tests will be presented. Photomicrographs of the mineralogical textures of the ISV product will also be prepared.

Based on the experience in operation and performance of the off-gas hood and filtration system, detailed procedures for ISV operations for all of the ORNL seepage pits and trenches will be developed. Critical parameters and methods for site characterization at each of the pits and trenches will be prioritized by demonstrating how the parameters were used in planning ISV operations during this treatability study. The experience at full-scale operation of ISV on ORNL pit 1 will result in accurate time and cost estimates for actual operations for these WAG 7 waste management units. In addition, operational performance information will be available for other types of waste management units (i.e., buried waste and underground storage tanks). 


\section{HEALTH AND SAFETY PLAN}

\subsection{INTRODUCTION}

In FY 1993, the following required documentation will be completed: NEPA approval request for categorical exclusion of this treatability study or continuity of operations project review checklist, Safety Assessment, Quality Assurance Plan, Project Management Plan, Readiness Review Summary, Waste Management Plan, Air Emissions Permit Application, and Treatability Study Work Plan (this document) for regulatory agency review. It is anticipated that the regulatory agency-DOE-ORNL working group can address any issues and concerns during the review process. In addition, this work plan will be reviewed and modified, where possible, by personnel in other DOE site ISV projects so that other technical objectives that might be attained during field testing can be incorporated if they do not compromise any major objective of this treatability study. The actual operation of the ISV pilot-scale process equipment is described in a separate PNL document entitled, "In Situ Vitrification Pilot-Scale System" (Battelle Pacific Northwest Laboratory 1991). This document discusses potential hazards (e.g., electrical shock, high temperature, toxic fumes and dust, and radiation) that must be dealt with during ISV. It is anticipated that this document, or the corresponding document for the large-scale process equipment, will be revised for the new electrode power delivery system (1.25 MW) when this is incorporated into the pilot-scale system later in 1993. Likewise, it will also be updated for the operation of the new off-gas hood and filtration system for this treatability study. It also describes all potential system failures, consequences, and operator actions. This document will be the primary personnel health and safety hazard communication vehicle for the ISV operations phase of this treatability study.

Both pretest and posttest characterization activities at the pit 1 site, including soil, groundwater, and sludge sampling, will conform to an existing ORNL Environmental Sciences Division Chemical Hygiene Plan (1992) with explicit amendments as described in this health and safety plan. All principal investigators and site workers will be required to complete $40 \mathrm{~h}$ of SARA/OSHA training and radiation worker training. All workers in pretest and posttest site characterization will be required to undergo routine whole-body counts and urine analyses. All site workers during ISV process operations will be required to undergo wholebody counts and urine analyses before and immediately after site operations.

\section{SITE DESCRIPTION}

Pit 1 was constructed in August 1951 by digging a 30 by $115 \mathrm{ft}$ trench (Fig. 2) into weathered shale residuum to a maximum nominal depth of $15 \mathrm{ft}$. In the following 3 months, pit 1 is estimated to have received about $389 \mathrm{Ci}$ of mixed fission products, about $200 \mathrm{~kg}$ of depleted uranium, and $266 \mathrm{mg}$ of plutonium as sludge suspended in highly alkaline liquid waste (approximately 123,000 gal). This pit was a proof-of-principle operation, and, although it leaked into a nearby drainage, a larger pit 2 was constructed in 1952, becoming the operational disposal unit for liquid radioactive waste at ORNL. Although not used for routine liquid waste disposal after 1951, pit 1 did receive additional discharges via a buried pipeline from drains in the nearby decontamination building (7819) between 1962 and 1970. 
These discharges of acids, soaps, and chelating agents were not monitored, but this contact-handled equipment decontamination facility probably did not add significantly to the inventory of radioactivity in pit 1 . During this and previous operations, pit 1 was spanned by a wooden frame roof with asphalt-coated corrugated metal sheeting to prevent infiltration of precipitation (Fig. 3). In 1981, the pit was filled with soil and capped with asphaltic concrete. Since that time the pavement has been resealed occasionally with various asphaltic coatings and the site surrounded by a 4-ft-high barbed-wire fence with appropriate radiation hazard warning signs (Fig. 4). Detailed maps of surface gamma exposure rates over and around pit 1 were collected and reported in 1989 (Carrier et al.); the maximum exposure rate observed was $10 \mathrm{mR} / \mathrm{h}$ at a well-defined location south and downslope of the pit, while rates over the pit range between 0.017 and $0.050 \mathrm{mR} / \mathrm{h}$. Background exposure rates at uncontaminated locations on the Oak Ridge Reservation average between 0.010 and $0.017 \mathrm{mR} / \mathrm{h}$. A map of the surface exposure rates on and around pit 1, from Carrier et al. (1989), is reproduced in Fig. 9.

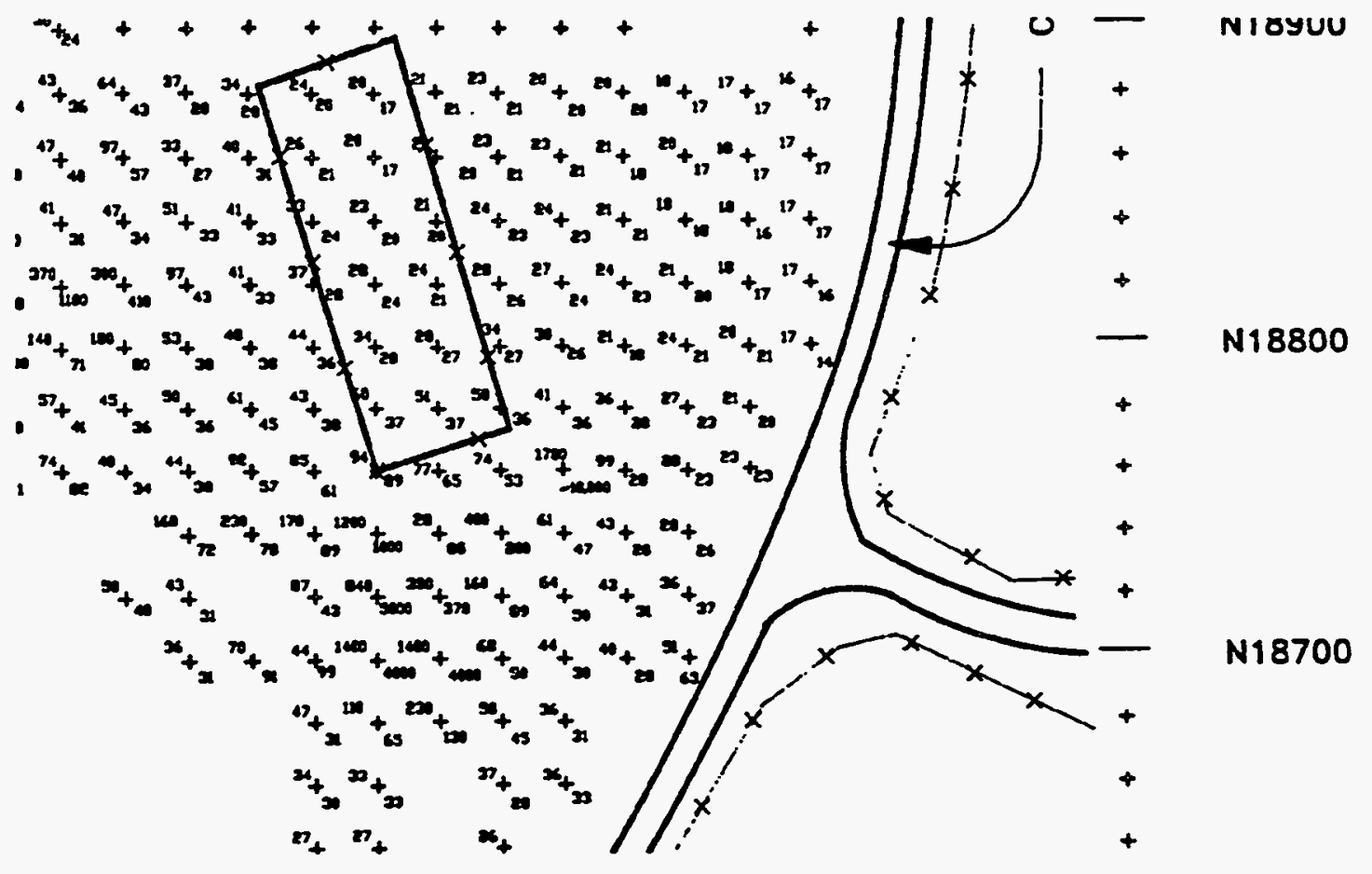

Fig 9. Survey of gamma dose rates $(\mu R / h)$ at $1 \mathrm{~m}$ above the surface and at the ground surface at ORNL Pit 1 (from Carrier et al 1989).

\section{ENTRY OBJECTIVES}

The objectives of site entry will be to perform site characterization and sampling that will, in turn, support design of further site entry for actual ISV of a significant portion (e.g., 25\%) of the radioactive contaminants in seepage pit 1 . The objectives for final site entry will be to sample the ISV product, to determine its quality, and to monitor site performance. 


\subsection{ON-SITE ORGANIZATION AND COORDINATION}

The following personnel are designated to carry out the stated job functions on site.

Project Team Leader:

Site Safety Officer:

Recordkeeper:

PNL ISV Operations Coordinator:

ISV Operations Personnel:
Brain Spalding

Michael Naney or designate

Gary Jacobs or designate

John Tixier

To be determined.

The project team leader is responsible for completing all tasks in this work plan. The site safety officer is responsible for preparing the site health and safety plan, determining if site workers meet training requirements, and assuring that site health and safety procedures are employed correctly. All personnel arriving or departing the site during site characterization activities or ISV operations will $\log$ in and $\log$ out with the recordkeeper. The recordkeeper is also responsible for maintenance of all site records and permits. All activities at the site must be cleared through the project team leader. The PNL ISV operations coordinator is responsible for the design, fabrication, and maintenance of ISV equipment, and for identification and training of ISV operations personnel during filed melting activities. ISV operations personnel will be responsible for operations of ISV equipment during site melting activities; this will include a minimum of one engineer or scientist and one technician per 8-h shift during field operations.

\subsection{LOCAL AGENCY REPRESENTATIVES}

The current organizational site custodian is R. G. Jones, ORNL Waste Management Remedial Actions, Building 3001, Mail Stop 6028, 574-7115; he will be informed of all site operations and planning activities, and he or his designate will approve all safety and radiation work permits for site operations.

\subsection{ON-SITE CONTROL}

Casual site visitation is already controlled by the Melton Valley Area access gate (guard post 24). A magnetic badge reader operates the vehicular gate approximately $100 \mathrm{ft}$ from pit 1; valid badges numbers are required to operate this gate and access requests require various training and supervisory approvals. Near the pit 1 site, a safe perimeter will be established at a minimum of $20 \mathrm{ft}$ from operations for both site characterization activities and ISV operations. A portable rope or chain barrier will be placed around the potentially hazardous site operations with appropriate warning labels; for site characterization activities on the present asphalt pad, the existing barbed-wire fence will be used as a boundary for an exclusion zone. No unauthorized person or casual site visitor will be allowed within this area. The safe perimeter will define an exclusion zone as necessary depending on the particular site activity. An on-site command post and staging area will be established at least $50 \mathrm{ft}$ from the safe perimeter to monitor site entry. 


\subsection{HAZARDS EVALUATION}

Hazards associated with conducting this treatability study at ORNL seepage pit 1 center on potential exposures to and releases of radioactivity presently contained in the pit. Thus, both personnel and environmental monitoring in real time can be performed on site without elaborate analytical equipment. As discussed above, gamma exposure rates at the present ground surface of pit 1 are quite minimal and pose no potential for exceeding dose limitations (i.e., 100 mrem whole body per year) for radiation workers even for continuous work operations on pit 1 . The highly localized higher dose $(10 \mathrm{mR} / \mathrm{h})$ region south of the pit will be marked and not available for casual entry. After ISV has been carried out at the site, direct gamma exposure rates from the resulting subsidence craters will be quite significant (i.e., 1-10 R/h) and, until covered by uncontaminated soil fill, present a significant potential for personnel exposure.

A more important potential avenue for personnel exposure would be inhalation or ingestion of airborne or water-borne radionuclides during various site operations. This could result from accidental release of pit contents during site characterization or ISV operations. During the initial phase of pit 1 characterization, no retrieval of pit samples will be attempted because only driven rods and pipes will be employed for in situ logging of radioactivity. After assessment of the radionuclide distribution in phase 1 , samples of pit contents and surrounding soils and groundwater will be taken; these second phase site characterization operations represents the potential for internal exposures of project personnel through either inhalation or ingestion. Direct exposure will also be a potential hazard when handling retrieved materials; however, the phase 1 in situ radioactive logging activities should provide good estimates of exposure rates, so that field operations and sample handling can be planned prior to actual field activities.

During ISV operations, potential for exposures will exist due to direct exposure, inhalation, and ingestion. In addition, there will be both an extremely hot heat hazard associated with the molten materials present and a high voltage danger due to the electrical power being processed by the ISV equipment. The temperature, electrical, and associated mechanical hazards associated with ISV equipment operations are discussed and addressed in the equipment safe operating procedures (Battelle Pacific Northwest Laboratory 1991). Assuming the off-gas hood and piping provides adequate containment of any volatilized radionuclides, the inhalation and ingestion exposure pathways would be eliminated. However, direct exposure rate from the off-gas hood interior surfaces or from the surface of the melt may limit personnel activities for some to-be-determined distance around the connection of the primary off-gas filtration subsystem.

After finishing ISV operations and allowing solidification of the molten product, uncontaminated soil will be used to cover and level the resulting subsidence zone; this fill should provide adequate shielding to reduce direct exposure rates similar to the present capping condition of pit 1 . However, a significant exposure pathway will be encountered during subsequent moving of the off-gas hood if significant volatilization of ${ }^{137} \mathrm{Cs}$ occurred during ISV. The off-gas hood and line decontamination and demobilization planning will address techniques to handle potential airborne releases during or before hood movement from one setting to another and again at the completion of site melting operations and subsequent hood storage. Coring of the resulting ISV product also represents a potential exposure pathway for personnel involved in that operation. Again direct exposure from the 
limited amount of product to be sampled will be known prior to actual sampling operations so that work times, shielding, and procedures can be planned accordingly. More importantly, potential exposure routes through inhalation or ingestion will exist during coring operations and subsequent sample handling and analyses.

During all phases of site operations, personnel will be susceptible to various environmental stresses and biological hazards, including heat stress and stroke, hypothermia in cold weather, frost bite, lightning, insect and snake bites, allergenic plants (e.g., poison ivy), falling trees, uneven ground, blood-borne pathogens and diseases. None of these hazards is unique to this site, and no special equipment, other than personnel training, will be necessary to deal with these hazards.

\subsection{EMPLOYEE TRAINING}

All personnel involved in pit 1 site characterization, both pre-vitrification and postvitrification, will be required by the project manager to have completed $40 \mathrm{~h}$ of SARA/OSHA training, to have maintained the currency of that training by attending an 8-h annual refresher training, and to obtain DOE-required radiation worker training and updates as required. All personnel will be required to maintain training and certified fitting for full- and half-face respirators, which will be required for certain field operations. At least one project principal investigator will maintain training as a certified solid low-level radioactive waste generator and as a RCRA satellite accumulation area operator. Site specific training will be provided by the project manager to all personnel who meet the training requirements listed here and who perform tasks at the site without escort by other trained personnel. Site specific training will include briefing of summary information about site contaminants, site history, and emergency procedures.

\subsection{PERSONAL PROTECTIVE EQUIPMENT}

Outside of the safe perimeter, no personal protective clothing is required, and, thus, personal clothing will be allowed. Inside the exclusion zone, based on an evaluation of potential hazards (radionuclides) and various job functions, different levels of personal protective clothing will be required: 


\begin{tabular}{lc}
\hline \multicolumn{1}{c}{ Job Function } & Level of Protection \\
\hline Penetration testing* & $\mathrm{C}$ \\
Pipe driving* & $\mathrm{C}$ \\
Well point driving & $\mathrm{C}$ \\
Site surveillance & $\mathrm{D}$ \\
Groundwater level monitoring & $\mathrm{D}$ \\
Soil sampling & $\mathrm{C}$ \\
Groundwater sampling & $\mathrm{C}$ \\
Pit sludge sampling & $\mathrm{C}$ \\
Site ISV preparations & $\mathrm{D}$ \\
ISV equipment setup & $\mathrm{D}$ \\
ISV operations & $\mathrm{C}$ \\
ISV off-gas hood movement & $\mathrm{C}$ \\
ISV decontamination & $\mathrm{C}$ \\
ISV equipment demobilization & $\mathrm{D}$ \\
ISV product sampling & $\mathrm{C}$ \\
Subsidence backfilling & $\mathrm{C}$ \\
Site regrading and paving & $\mathrm{D}$ \\
\hline
\end{tabular}

\footnotetext{
These job functions may be downgraded from level $C$ to level $D$ protective clothing requirements if routine Radiation Protection and Industrial Hygiene Sections monitoring fail to determine any hazard and if the Sections agree to this in writing on the radiation work permit and safety work permits.
}

Specific personal protective equipment for each level of protection is described below:

Level C: Full-face respirator with air-purifying cartridges (combination HEPA and activated charcoal); chemical-resistant clothing (Tyvek jacket and pants); chemical-resistant rubber gloves, rubber boots, and hard hat (if any overhead operations are involved).

Level D: Regulated-zone yellow coveralls (with or without company-issued clothing underneath), safety shoes or boots, safety glasses or chemical splash goggles, hard hat (if any overhead operations are involved), and rubber gloves (if measuring groundwater levels or if handling any environmental samples regardless of radiation detector readings).

Decontamination of personnel is planned only as a contingency action. All personnel protective equipment (except respirators) will be selected for disposal after completion of use. If personnel decontamination is required, as directed and monitored by Radiation Protection personnel, decontamination will be attempted initially by water rinses with a hand-pump sprayer of clean water maintained on site. If further decontamination is required on site, detergents and scrubbing will be used on the affected areas of the skin (not personal protective clothing). Follow-up radiation assays, including skin smears and surveys, nasal smears. sputum samples, urine and fecal sampling, and whole-body radioassays, will be performed at the direction of Radiation Protection personnel.

During rod penetration testing and pipe or well screen driving, additional containment will be provided against possible airborne releases. The pipe or rod will be driven through a hole in a surrounding plastic sheet (roughly $3 \mathrm{ft}^{2}$ ). A continuous plastic bagging will be sealed 
to the plastic sheet with vinyl adhesive tape and, with the rod or pipe inside the sleeve, sealed again with vinyl tape near its point of attachment to the driving tool (airless or electric jackhammer). In this manner, any airborne releases originating from the penetration point and transported to the surface in the annular space between tool and drive hole will be contained within plastic material; radiation surveys can be completed on the ground surface and with the tool-in-a-bag before removing the containing plastic. This secondary containment of driving tools is performed as a personnel protection measure against inadvertent potential airborne releases and exposures. It is not planned to remove the rod or pipe from the pit 1 site until in situ radiation logging of the pipes allows an assessment of the dose rates to be handled; neither steel rods nor galvanized pipe removals are necessary, since inclusion of these metals will not affect ISV operations on pit 1.

\subsection{MEDICAL SURVEILIANCE}

Personnel employed by Energy Systems are scheduled for regular medical surveillance and examinations. In addition, because of the project requirement for certified fitting for respirators, all project personnel are required to obtain approval to be fitted with respiratory protection by the Energy Systems medical department (Health Division) at 12-month intervals prior to annual respirator training and fitting. Personnel of PNL (another DOE prime contractor) are subject to the same medical surveillance and respirator fitting and training requirements and have an equivalent program at that institution. Additional personnel monitoring, related to medical surveillance, is described in personnel and environmental monitoring (Sect. 9.7).

\subsection{PERSONAL AND ENVIRONMENTAL MONITORING}

All operations and job functions (including those listed in Sect. 9.9) will be performed in compliance with procedures and guidance in the ORNL Health Physics Manual (ORNL 1990). Radiation protection monitoring by Martin Marietta Energy Systems Radiation Protection personnel will be specified by Radiation Work Permits (RWPs), when required, for each daily operation. An RWP is a written authorization for one or more named employees to do a particular job which may involve exposure to a specified amount of radiation or contamination. It describes the proposed work, the radiation conditions to be encountered, and the working restrictions and other protective measures that are required. Each job function or site operation at pit 1 will likely have different protective equipment and monitoring requirements. Depending on planned exposures or likelihood of contamination during operations with poorly defined levels of contamination during a particular job, a Radiation Protection technician may be required continuously, intermittently, initially, at job termination, or not at all at the site during operations.

Because the primary hazards at the pit 1 site are posed by radionuclides and the most probable route of exposure is by possible airborne releases with subsequent inhalation or ingestion, personal monitoring will focus on air sampling and personal dosimetry. A highvolume particulate air sampler will be operated during penetration tests and pipe insertions at the pit 1 site. The frequency of this air sampling will be determined during initial operations after consultations with Radiation Protection personnel. In addition, personnel will have personal daily direct-reading dosimeters during any penetration or insertion operations 
at the site; these will be signed out and logged daily and readings recorded on the radiation work permit. Real-time radiation hazards will be assessed through the use of portable beta/gamma (Geiger-Mueller) meters and alpha detectors, which will be employed daily during site operations. As a final option, the regular badge dosimeter of personnel can be assayed at any time, rather than at the regular quarterly interval, should unusual exposures be suspected.

During initial operations at the site, personnel exposure to potential organic vapors will be assessed by intermittent sampling of ambient air and air space around penetration test points using an organic vapor analyzer; if unusual levels above background are encountered, additional air samples will be taken for analyses of specific volatile organic compounds. After assessment of possible organic vapors at the site, initial samples of any standing water in the driven well points will be analyzed for volatile and semivolatile organic species and for elemental contaminants as an aid in determining hazards associated with groundwater sampling and water table elevation measurement in the area.

The expected air temperatures at the pit 1 site will vary between 10 and $100^{\circ} \mathrm{F}$ during the year; personnel will monitor their body weight at the end of the day to assess any heat stress imposed by use of protective equipment. Heat and cold stress symptoms are discussed in the required SARA/OSHA training for site personnel; thus, personnel will be personally responsible for monitoring their own physical condition during site activities.

\title{
9.12 EMERGENCY RESPONSE PLAN
}

There will be no emergency medical technicians on site. The designated medical facilities are:

\author{
Health Division \\ Oak Ridge National Laboratory \\ Building 4500N \\ Emergency Phone: 911 \\ Distance from site: 2 miles or 5 minutes.
}

Local ambulance service is available at the fire hall at ORNL and is also available by dialing 911 or radio call and is located 1.5 miles (4 min) from the site. Emergency first-aid equipment is not available at the work site because medical service is available within such a short distance. Because the potential hazardous substances at pit 1 are solely radionuclides, material safety data sheets are not available for these substances. If the skin or eyes are exposed, they should be washed and rinsed. A portable emergency eyewash will be maintained at the site as well as a supply of clean water (55-gal drum) for personnel decontamination operations and a hand-pump 5-gal sprayer for emergency decontamination. If hazardous materials are swallowed or ingested, vomiting should be induced and medical aid sought.

\subsection{Emergency Procedures}

The following standard emergency procedures will be used on site by all personnel. The site safety officer shall be notified of any site emergencies and shall be responsible for ensuring that appropriate procedures are followed: 
Personnel injury in the exclusion zone: Upon notification of an injury in the exclusion zone, the designated emergency signal of either three horn blasts or verbal imperative, "Help! Help! Help!" will be sounded. All site personnel shall assemble at the entrance point. The rescue team will enter the exclusion zone (if required) to remove the injured person. The site safety officer and the project team leader should evaluate the nature of injury and the affected person should be decontaminated, if needed, to the extent possible. If injury is determined to be an immediate threat to life, decontamination procedures will be postponed until the injured person is stabilized. Contact should be made by radio for an ambulance. No persons should reenter the exclusion zone until the cause of the injury or symptoms has been determined.

Personnel injury outside the exclusion zone: Upon notification of an injury, the designated emergency signal of three horn blasts or verbal imperative, "Help! Help! Help!" shall be sounded. All personnel shall assemble at the command post. The rescue team will not move the injured person. The site safety officer and the project team leader shall evaluate the nature of the injury. Contact should be made by radio for an ambulance. No person should restart work until the cause of the injury or symptoms has been determined.

Fire/explosion: Upon notification of a fire or explosion on site, the designated emergency signal of three horn blasts or verbal imperative, "Stop! Get Out!" shall be sounded and all site personnel will assemble at the command post. The fire department shall be notified by radio and all personnel move to a safe distance from the involved area.

Personal protective equipment failure: If any site worker experiences a failure or alteration of protective equipment that affects its protection factor, that person shall immediately leave the exclusion zone. Reentry shall not be permitted until the equipment has been replaced or repaired.

Other equipment failure: If any other equipment on site fails to operate properly, the project team leader and site safety officer shall be notified and shall determine the effect of the failure on continuing operations at the site. If the failure affects the safety of personnel or prevents completion of the work plan tasks, all personnel shall leave the exclusion zone until the situation has been evaluated and appropriate actions taken.

In all situations, when a site emergency results in evacuation of the exclusion zone, personnel shall not reenter until

1. the conditions resulting in the emergency have been corrected,

2. the hazards have been reassessed,

3. the site safety plan has been reviewed, and

4. site personnel have been briefed on any changes in the site safety plan.

\subsection{Emergency Escape Route}

The following emergency escape routes are designated for use in situations where egress from the exclusion zone cannot occur through the designated entrance: Proceed south towards Building 7874. 


\subsection{Emergency Contacts}

Emergency Telephone Numbers

All emergencies $\quad 911$

Fire Department 911

Nonemergency Telephone Numbers

$\begin{array}{ll}\text { Guard Headquarters } & 4-6646 \\ \text { ORNL Shift Supervisor } & 4-6606 \\ \text { Environmental Management } & 4-6670 \\ \text { Radiation Protection } & 4-6654 \\ \text { Industrial Safety } & 4-6688 \\ \text { Industrial Hygiene } & 4-6165 \\ \text { Health (Medical) Center } & 47431\end{array}$

\subsection{CONFINED-SPACE ENTRY PROCEDURES}

No confined spaces are anticipated for any pretest or posttest site characterization activities. During ISV operations, the off-gas hood, after its initial use in ISV operations, may be designated a confined space and require appropriate training and monitoring for entry.

\subsection{SPILL CONTAINMENT PROGRAM}

No hazardous liquids will be on site during pretest site characterizations; thus, no spill containment procedures will be developed or emergency response materials procured. During ISV operations, the ISV off-gas processing trailer will contain off-gas scrub solutions in predefined sections of the trailer; these will be secondarily contained using portable berms under those sections of the equipment trailer. Final off-gas scrub solutions will be stored in secondary containers of sufficient capacity until analyses and disposal are completed. During ISV operations, spill containment equipment (sorbent pads and pillows) will be maintained on site. During posttest ISV product sampling, spill containment equipment and sorbent materials will be kept on site of sufficient capacity to handle the volume of hydraulic fluid within the drill rig used for core sampling.

\subsection{COMMUNICATION PROCEDURES}

All personnel involved in site characterization activities will maintain radio communications while at the pit 1 site; the government vehicle will have a radio for ORNL communication and emergency use, and at least one site worker will carry a battery-operated portable radio during site operations. During ISV operations either a hard-wired telephone will be installed at the site or a dedicated radiotelephone will be available for on- and off-site communications by operations personnel. During site operations personnel will remain within 
site of the project team leader or his designate. A triple horn blast from any transportation vehicle is the emergency signal that all personnel should leave the exclusion zone. During any operation where site personnel are wearing level $\mathrm{C}$ personal protective clothing and respirators, making verbal communication difficult, personnel will wear voice-activated FMfrequency personal communicators with microphones proximate to the throat outside the respirator; this hands-free communication allows low-volume verbal communication among site workers without compromising any protection integrity. All site workers will be trained in the use of the following standard hand signals, to be used in case of radio communications failure:

$\begin{array}{ll}\text { Signal } & \text { Meaning } \\ \text { Grip wrist } & \text { Leave area immediately } \\ \text { Both hands around waist } & \begin{array}{l}\text { Leave area immediately } \\ \text { Hands on top of head }\end{array} \\ \text { Need assistance } \\ \text { Thumbs up } & \text { OK, I am all right, or I understand } \\ \text { Thumbs down } & \text { No, negative. }\end{array}$

\subsection{HEALTH AND SAFETY REFERENCES}

The procedures and operations of this site health and safety plan are in conformance with the following health and safety programs:

Worker Protection in Hazardous Waste Operations and Emergency Response. ESP-IH161. Martin Marietta Energy Systems, Inc., procedure.

Hazardous Waste Operations and Emergency Response (HAZWOPER). PRG-IH-17. ORNL Safety and Health Program for 29 CFR 1910.120.

ORNL Hazardous Waste Operations and Emergency Response Program. IHP-17. Oak Ridge National Laboratory, Industrial Hygiene procedure.

OSHA Training Requirements for Hazardous Waste Operations. DOE/EH-0227P. U.S. Department of Energy, Office of Environment, Safety, and Health (EH), December 1991.

Environmental Sciences Division. 1992 Chemical Hygiene Plan. Oak Ridge National Laboratory, Oak Ridge, Tennessee.

ORNL Health Physics Manual. 1990. ORNL/M-804. Martin Marietta Energy Systems, Inc., Oak Ridge, Tennessee. 


\section{RESIDUALS MANAGEMENT}

The fused ISV product blocks will be left in place at the pit 1 site after completion of the field operations. Subsidence craters will be filled with clean soil, graded to existing contours, and the area recapped with asphaltic concrete to maintain the integrity of the existing cap. Key groundwater monitoring wells will be maintained for continuing assessment of ISV impacts at the pit 1 site. All samples of groundwater, soils, pit sludge, and ISV product will be stored in Building 1505 until completion of the treatability study report and data quality checks have been completed. Excess materials will be disposed of as radioactive, hazardous, or mixed waste according to existing ORNL systems as appropriate. It is anticipated that no mixed waste will be generated, although, without any pit 1 site characterization information at present, the potential for generating mixed waste cannot be ruled out. Off-gas scrub solutions from the ISV processing trailer are anticipated to be hazardous liquid waste due to the inherent acidity of the off-gas. The prefilter system should remove all radioactive isotopes prior to off-gas scrubbing. Any residual radioactive contamination on the off-gas hood will be stabilized by coating the inside surfaces of the hood. The hood will be stored for future use in ORNL WAG 7 when ISV operations are initiated for site closure. If ISV is not selected for site remediation, the residual off-gas hood will be disposed of as radioactive solid waste or considered for use at other DOE sites. 


\section{COMMUNITY RELATIONS PLAN}

Prior to initiating field activities at ORNL seepage pit 1, a four-page flier will be prepared describing the site needs, ISV technology and its capabilities, and the goals for the treatability study; the flier will be oriented for a nontechnical audience. In addition to making these flyers available at various technical meetings, they will be made available during public meetings conducted by DOE's Environmental Restoration and Waste Management Division when remedial actions are proposed for public comment. Poster display material will supplement these fliers and gratis samples of the nonhazardous, nonradioactive ISV product from the 1987 test at ORNL will be made available. The fliers will also be made available, along with sample materials, at the Information Resource Center (IRC) in Oak Ridge. Previously published materials will be made available to individuals upon request, and their availability will be advertised in the flier; group briefings will be made to interested organizations or groups upon request. For group briefings and educational presentations, a beaker-scale ISV demonstration, using 110-V single-phase power, will be developed to aid public appreciation of the inherent simplicity of the ISV process and the modest levels of electricity required to melt soil by ISV; the common public impression that regional "brownouts" and, thus, high cost would result if ISV were performed at actual scale needs to be overcome. As in previous demonstrations, provisions will be made for visitors and press coverage during actual ISV field operations. Invitations to join these tours during the study will be sent to all local environmental advisory groups and press organizations. An updated flier will be prepared for these site tours describing the site, ISV technology, and the goals of the study. In addition, various releases of progress information and interim reports will be made, with copies distributed to both the DOE technical community and information newsletters. 


\section{REPORTS}

Several reporting milestones will be established over the multiyear effort of this treatability study. Obviously, the treatability study report will be prepared at the end of FY 1995 (September 1995) as indicated in the project schedule. A minimum of two interim project progress reports will be prepared at the ends of FY 1993 and 1994. The FY 1993 report will focus on the progress of the environmental, safety, and health documentation, which is required for the project; the initial phase of pit 1 site characterization; and the laboratory assessment of factors contributing to volatilization of ${ }^{137} \mathrm{Cs}$. The FY 1994 report will summarize all pretest pit 1 site characterization, document the design and fabrication of the off-gas hood and filtration system for the study, and contain the final run plan for the field melt operations. The final treatability study report will summarize all project information with detailed ISV performance process analysis, posttest product characterization and leaching studies, site restoration, the recommended continuing site monitoring plan, and complete feasibility and economic analyses of ISV for the ORNL seepage pits and trenches. 


\section{SCHEDULE}

The proposed schedule for this treatability study and the activities in WAG 7, which it supports, is depicted in Fig. 10. The timely completion of the treatability study draft report by September 1995 is critical to the support of an IROD or ROD for closure of one, several, or all of the seepage pits and trenches in WAG 7 (Fig. 10). An IROD could then be produced by January 1996 with completion of closure(s) by June of 1997 . The RI/FS for the entire WAG 7 will probably begin late in FY 1994 and would probably result in a ROD for the entire WAG 7 in FY 1998. Obviously, completing an IROD by that time should facilitate the process of ROD approval for WAG 7. ISV will probably be used only for the closure of the seven seepage pits and trenches, while the ROD for all of WAG 7 will include other methods for containing the peripheral contaminated soil and sediments as well as the above ground contaminated facilities in WAG 7.

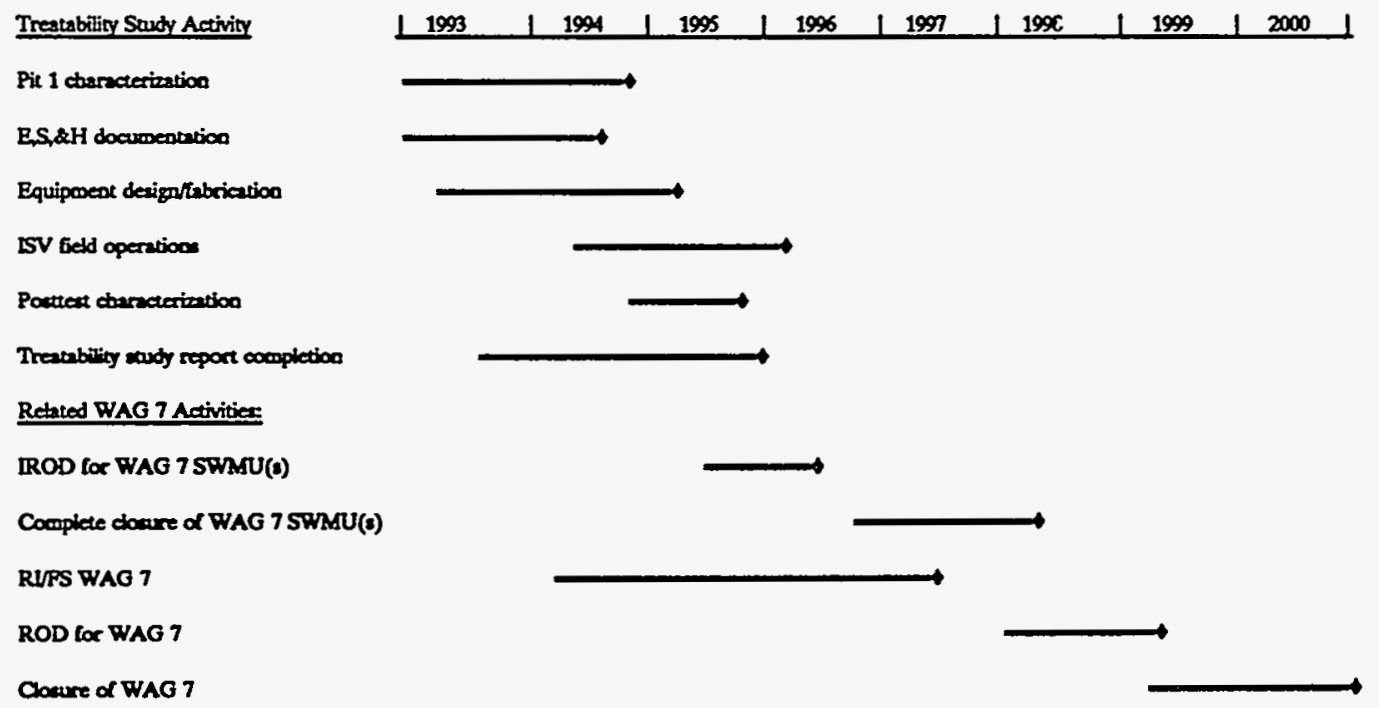

Fig. 10. Schedule for the ORNL pit 1 ISV treatability study and supported WAG 7 closure activities. 


\section{MANAGEMENT AND STAFFING}

Martin Marietta Energy Systems personnel will be responsible for pit 1 site characterization, site preparation, support services for Battelle personnel when on site for ISV operations, and posttest sampling, analyses, and reporting. Brian P. Spalding will be the project manager, and Gary K. Jacobs and Michael T. Naney will be principal investigators.

Battelle Pacific Northwest Laboratory personnel will be responsible for producing an ISV run plan compatible with pit 1 site characterization and study objectives; off-gas hood design, fabrication, and procurement; and off-gas prefiltration system design, fabrication, and procurement. They will also be responsible for performing or subcontracting for services to perform the ISV site operations and transportation of ISV equipment to and from ORNL and for contributing to the operational performance assessment of the final report. John S. Tixier will be the Battelle project manager. 


\section{BUDGET}

The estimated costs for the treatability study are presented in Table 2 for FY 1993 through 1995.

Table II. Estimated costs (in thousands) for the Pit 1 ISV treatability study by fiscal year

Subtask Activity

Pretest Site Characterization

E,S,\& H Documentation

Equipment Design and Fabrication

Equipment Testing

ISV Field Operations

Posttest Characterization

Treatability Study Report

Total Treatability Study
FY1993

200

211

50

$\mathbf{0}$

0

0

0

461

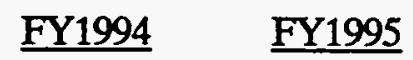

200

0

350

0

850

0

300

0

600

600

0

550

200

300

2500 


\section{REFERENCES}

Battelle Pacific Northwest Laboratory. 1991. "In Situ Vitrification Pilot-Scale Test System Safe Operating Procedure." Procedure 49, Revision 8. Battelle Pacific Northwest Laboratory, Richland, Washington, 32pp.

Buelt, J. L., C. L. Timmerman, K. H. Oma, V. F. Fitzpatrick, and J, G. Carter. 1987. In situ vitrification of transuranic waste: Systems evaluation and applications assessment. PNL. 4800, Supplement 1. Battelle Pacific Northwest Laboratory, Richland, Washington.

Callow, R. A., L. E. Thompson, J. R. Weidner, C. A. Loehr, B. P. McGrail, and S. O. Bates. 1991. In situ vitrification application to buried waste: Final report of intermediate field tests at Idaho National Engineering Laboratory. EGG-WTD-9807. Idaho National Engineering Laboratory, Idaho Falls, Idaho.

Carrier, R. F., J. K. Williams, and J. A. Roberts. 1989. Surface radiological investigations at pit 1 environs. ORNL/RAP/LTR-88/55. Oak Ridge National Laboratory, Oak Ridge, Tennessee.

Farnsworth, R. K, K. H. Oma, and C. E. Bigelow. 1990. Initial tests on in situ vitrification using electrode feeding techniques. PNL-7355. Battelle Pacific Northwest Laboratory, Richland, Washington.

Ghiorso, M. S. 1987. "Modeling magmatic systems: Thermodynamic relations." In Thermodynamic modeling of geologic materials: Minerals, fluids, and melts. I. S. E. Carmichael and H. P. Eugster (eds.), Reviews in Mineralogy 17:443-465. Mineralogical Society of America, Washington, D.C.

Janzten, C. M. and N. E. Bibler. 1989. Nuclear waste glass product consistency test (PCT) method. Version 3.0. Westinghouse Savannah River Company, Aiken, South Carolina.

Lomenick, T. F., D. G. Jacobs, and E. G. Struxness. 1967. "The behavior of strontium-90 and cesium-137 in seepage pits at ORNL." Health Physies. 13:897-905.

Shade, J. W. and G. F. Piepel. 1990. Viscosity, electrical conductivity, and cesium volatility of ORNL vitrified soils with limestone and sodium additives. PNL7331. Pacific Northwest Laboratory, Richland, Washington.

Spalding, B. P. and G. K. Jacobs. 1989. Evaluation of an in situ vitrification field demonstration of a simulated radioactive liquid waste disposal trench. ORNL/TM-10992. Oak Ridge National Laboratory, Oak Ridge, Tennessee.

Spalding, B. P., G. K. Jacobs, N. W. Dunbar, M. T. Naney, J. S. Tixier, and T. D. Powell. 1992. Tracer-level radioactive pilot-scale test of in situ vitrification for the stabilization of contaminated soil sites at ORNL. ORNL/TM-12201. Oak Ridge National Laboratory, Oak Ridge, Tennessee. 
Spalding, B. P., G. K. Jacobs, and E. C. Davis. 1989. Demonstrations of technology for remediation and closure of Oak Ridge National Laboratory waste disposal sites. ORNL/TM11286. Oak Ridge National Laboratory, Oak Ridge, Tennessee.

United States Environmental Protection Agency (U.S. EPA). 1989. Guide for conducting treatability studies under CERCLA Interim Final. EPA/540/2-89/058. Office of Research and Development, Cincinnati, Ohio.

United States Environmental Protection Agency (U.S. EPA). 1992. Handbook vitrification technologies for treatment of hazardous and radioactive waste. EPA/625/R-92/002 EPA, Office of Research and Development, Washington, D.C. 


\section{DISTRIBUTION}

1. V. Alexiades

2. C. A. Bednarz

3. M. A. Bogle

4. H. L. Boston

5. S. R. Cline

6. L. J. Degenhardt

7. J. W. Finchum

8. C. W. Francis

9. D. L. Garrett

10. R. J. Howard

11. G. K Jacobs

12. L. L. Kaiser

13-15. D. M. Matteo

16. M. T. Naney

17-18. P. T. Owen

19. W. R. Reed

20. A. W. Saulsbury

21. P. A. Schrandt

22. I. M. Smith

23-42. B. P. Spalding

43. T. W. Talley

44. F. G. Taylor

45. L. M. Tolbert

46. J. R. Trabalka

47. D. D. Van Hoesen

48. A. S. Will

49. P. S. Wood

50. Environmental Sciences Division Library

51. Central Research Library

52-53. ORNL ER Document Management Center

54. Central ER Document Management Center

55. Laboratory Records Department

56. ORNL Patent Section

57. Office of Assistant Manager for Energy Research and Development, DOE Oak Ridge Operations Office, P.O. Box 2001, Oak Ridge, TN 37831-8600

58. D. M. Carden, DOE Oak Ridge Operations Office, P.O. Box 2001, Oak Ridge, TN 37831-8541

59. J. O. Moore, DOE Oak Ridge Operations Office, P.O. Box 2001, Oak Ridge, TN 37831-8541

60. J. S. Sweeney, DOE Oak Ridge Operations Office, P.O. Box 2001, Oak Ridge, TN 37831-8541

61-62. Office of Scientific and Technical Information, P.O. Box 62, Oak Ridge, TN 37831 